\title{
COMPARATIVE STUDY OF FOUR PASSIVE ENERGY DISSIPATION SYSTEMS
}

\author{
Ian D. Aiken', Douglas K. Nims², and James M. Kelly
}

\begin{abstract}
SUMMARY
Passive energy dissipation devices have the potential to increase the seismic resistance of a structure by increasing its capability to dissipate energy and by reducing the seismic demand on the structure. They offer particular promise for seismic retrofitting as well as extensive applications in new construction.

This paper describes and compares earthquake simulator tests of four new types of passive energy dissipators that were performed at the Earthquake Engineering Research Center of the University of California at Berkeley. The four types of energy dissipator are a Coulomb friction damper; a self-centering friction device in which the slip load is proportional to the slip displacement; a viscoelastic shear damper; and a shape memory alloy. Two different model structures were used in the experimental studies, and the energy dissipators were incorporated as part of the bracing systems of the structures.
\end{abstract}

\section{INTRODUCTION}

Conventional seismic design practice permits the reduction of forces for design below the elastic level on the premise that inelastic action in a suitably designed structure will provide that structure with significant energy dissipation potential and enable it to survive a severe earthquake without collapse. This inelastic action is typically intended to occur in specially detailed critical regions of the structure, usually in the beams near or adjacent to the beam-column joints. Inelastic behaviour in these regions, while able to dissipate substantial energy, also often results in significant damage to the structural member, and although the regions may be well detailed, their hysteretic behaviour will degrade with repeated inelastic cycling. The interstory drifts required to achieve significant hysteretic energy dissipation in critical regions are large and would usually result in substantial damage to non-structural elements such as in-fill walls, partitions, doorways, and ceilings. As a response to the shortcomings inherent in the philosophy of conventional seismic design, a number of innovative approaches have been developed.

One of these approaches involves adding energy absorbers to a structure. The aim of including energy absorbers in a structure for earthquake resistance is to concentrate hysteretic behaviour in specially designed and detailed regions of the structure and to avoid inelastic behaviour in primary structural elements (except

${ }^{1}$ Earthquake Engineering Research Center, University of California at Berkeley (Member).

${ }^{2}$ Department of Civil Engineering, The University of Toledo, Ohio. perhaps under the most severe conditions). Numerous different types of energy-absorbing devices have been proposed for this purpose. Devices based on the plastic deformation of mild steel were developed and extensively tested a number of years ago. Friction devices of several types have been the subject of a number of test programmes, and one type was recently installed in a library building in Montreal. By the middle of 1991, the Sumitomo-type friction dampers studied here had been incorporated in 31- and 22-story buildings, both in Japan. Lead extrusion dampers have been used in a recently completed 11story building, and also in an 8-story building now under construction. Both of these buildings are in Japan. Viscoelastic dampers have been used in several tall buildings for wind vibration control. The dampers use a highly dissipative polymeric material which has well-defined material properties and behavioural characteristics [4]. The most notable applications are the twin 110-story towers of the World Trade Center in New York City, in which the dampers have been installed for 20 years. Several other high-rise buildings in the U.S. also use viscoelastic dampers for wind vibration control.

The role of a passive energy dissipator is to increase the hysteretic damping in the structure. The basic model of the structure is represented in the following equation:

$$
E_{1}=E_{K}+E_{S}+E_{V}+E_{H}
$$

where:

$$
\begin{aligned}
& \mathrm{E}_{\mathrm{I}}=\text { earthquake input energy } \\
& \mathrm{E}_{\mathrm{K}}=\text { kinetic energy in the structure } \\
& \mathrm{E}_{\mathrm{S}}=\text { strain energy in the structure } \\
& \mathrm{E}_{\mathrm{V}}=\text { viscous damping energy } \\
& \mathrm{E}_{\mathrm{H}}=\text { hysteretic damping energy }
\end{aligned}
$$


The role of this equation in the design process has been presented by Uang [8]. $E_{V}$ is a fixed property of the structure (assuming that significant yielding does not occur in the structure during earthquake shaking). $\mathrm{E}_{\mathrm{H}}$ is the energy absorbed by the energy dissipators. $E_{K}$ and $E_{I}$ also change as the characteristics of the energy dissipators change. This change is incidental, but unavoidable, because the energy dissipators modify the stiffness as well as the damping of the structure. $E_{\mathrm{I}}$ can increase or decrease depending on the frequency content of the earthquake signal. The goal is to increase $E_{H}$ so that for a given $E_{I}$, the strain energy in the structure is decreased. This means that the structure will undergo smaller deformations, for a given level of input energy, than if it did not include energy dissipators. Alternately, increasing $\mathrm{E}_{\mathrm{H}}$ permits $\mathrm{E}_{\mathrm{S}}$ to be reduced for a higher level of $\mathrm{E}_{\mathrm{I}}$.

\section{LARGE-SCALE EARTHQUAKE SIMULATOR TESTING OF FRICTION AND VISCOELASTIC DAMPERS.}

This section presents a summary of the results of the tests of the Sumitomo friction damper and the $3 \mathrm{M}$ viscoelastic shear damper. Both series of tests were performed using the same large-scale nine-story steel frame. A comprehensive presentation of the results of these shake table tests is given in [1].

\subsection{Description of test facility and model structure.}

The experimental programme was carried out using the earthquake simulator of the Earthquake Engineering Research Center of the University of California at Berkeley. The earthquake simulator (or shake table) measures $6.1 \mathrm{~m}$ by $6.1 \mathrm{~m}$ $(20 \mathrm{ft} \times 20 \mathrm{ft})$ in plan and can support test specimens weighing up to $580 \mathrm{kN}$ (130 kips). Simulated seismic motions can be applied vertically and in one horizontal direction, with maximum accelerations of $1.0 \mathrm{~g}$ and $1.5 \mathrm{~g}$ respectively. The basic test structure was a 9-story, moment-resisting steel frame representing a section of a typical steel building at 1/4-scale. The structure was tested as a moment-resisting frame (MRF), a concentrically-braced frame (CBF), and in friction-damped (FD) and viscoelastically-damped (VD) configurations (Figure 1). The VE dampers were added to the MRF in single-diagonal bracing (Figure 2), and the friction dampers were added as part of a modified chevron bracing system (Figure 3 ).
Constant stress scaling, such that model and prototype accelerations are equal, was used for the shake table tests. This required that approximately $400 \mathrm{kN}$ (90 kips) of weight be added to the model in the form of concrete blocks and lead billets. The total test weight of the model was $445 \mathrm{kN}$ (100 kips). Response quantities measured during the shake table tests included floor displacements and accelerations, bracing forces and damper displacements, base shear and base overturning moment, and shake table accelerations and displacements.

\subsection{Description of dampers}

The two types of devices studied were a viscoelastic (VE) shear damper and a sliding friction damper. The VE damper comprises two layers of material (Figure 4), and was introduced as single-diagonal bracing in the test structure (Figure 5). The VE material used in the dampers is an acrylic copolymer that has been developed by $3 \mathrm{M} \mathrm{Co.,} \mathrm{USA.} \mathrm{It} \mathrm{is} \mathrm{one} \mathrm{of} \mathrm{four} \mathrm{types} \mathrm{of}$ highly-dissipative polymer currently available from $3 \mathrm{M}$. The VE material behaviour is influenced by its shear loss modulus, the shear storage modulus, and their ratio, the material loss factor [4]. These properties are dependent on frequency, temperature, and deformation strain level, and the general relationship is the same for all of the materials. Thus, one general relationship can be used to predict the properties for all four materials. This is the basis of material property charts developed by the manufacturer. The friction damper was designed and developed by Sumitomo Metal Industries, Ltd., Japan. It is a cylindrical device, with friction pads that slide directly on the inner surface of the steel casing of the device (Figure 6). The friction devices were attached to the underside of the floor beams and connected to chevron brace assemblages (Figure 7). The device was originally used as a shock absorber in railway rolling stock. The mechanical characteristics of both types of dampers were well known from previous studies, and both have already been used in a number of structural or mechanical engineering applications. This experimental study represented the first use of the dampers for earthquake force conditions.

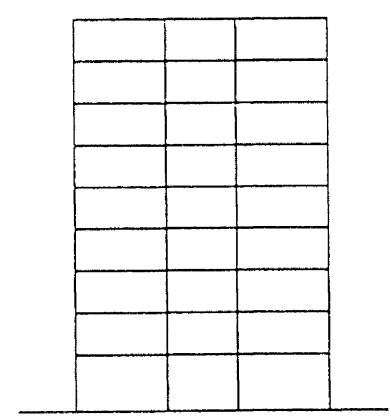

(a) MRF

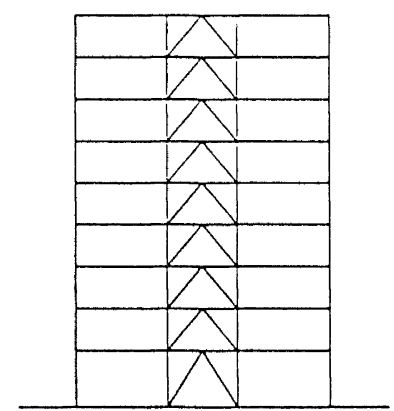

(b) CBF

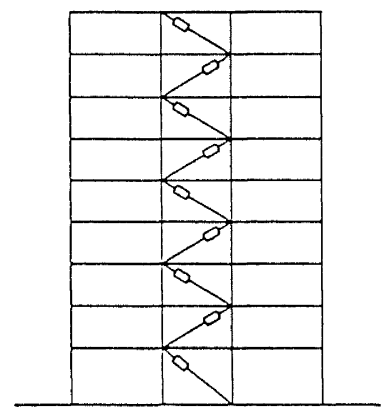

(c) VD

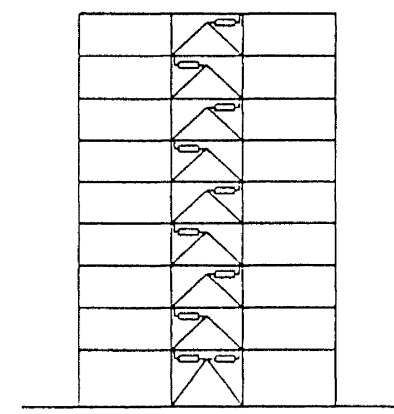

(d) FD 


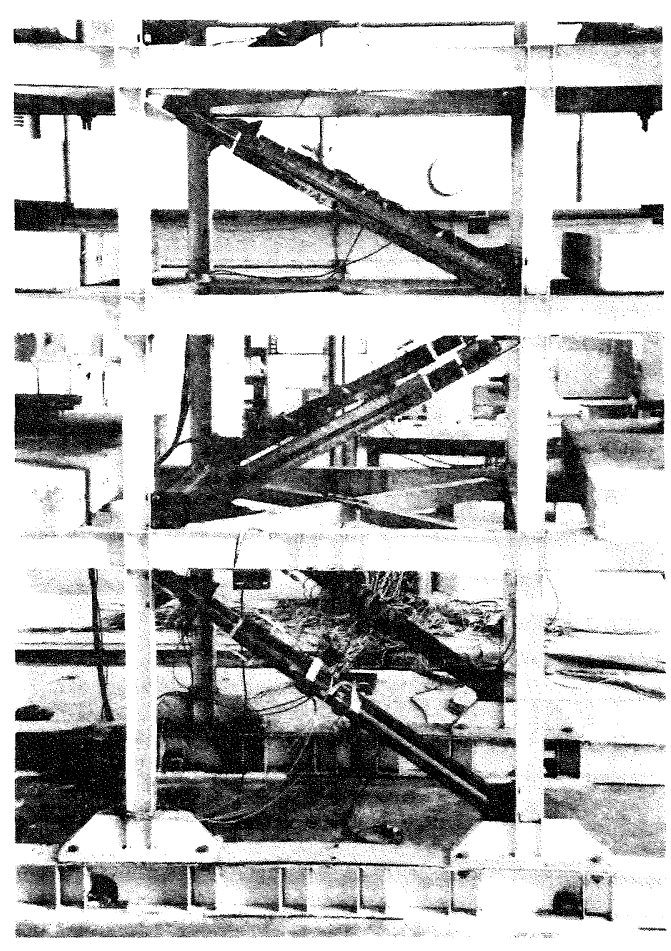

Fig. 2 View of Bottom Three Levels of Model With Viscoelastic Dampers

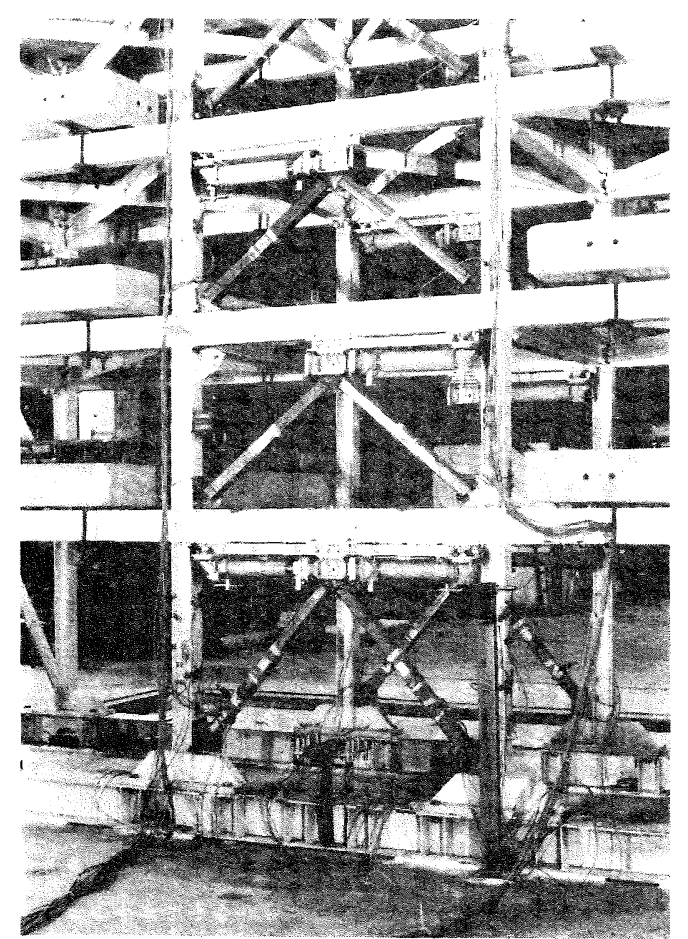

Fig. 3 View of Bottom Three Levels of Model With Friction Dampers

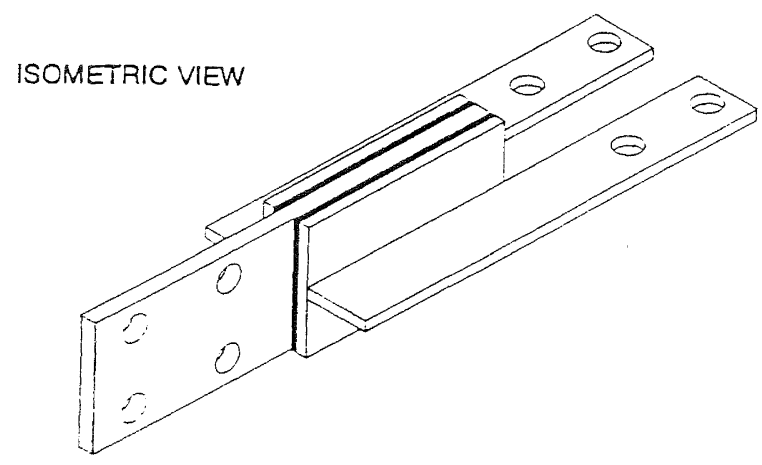

Fig. 4 VE Constrained-Layer Shear Damper 


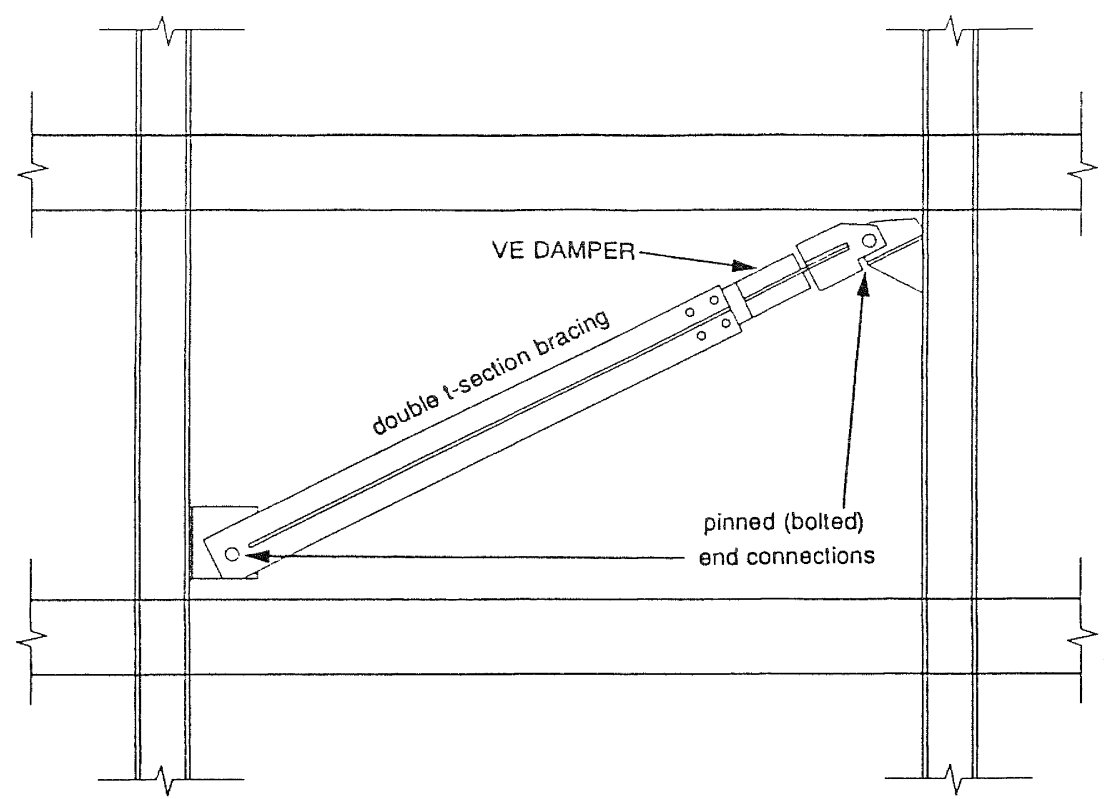

Fig. 5 Installation of VE Dampers in Model

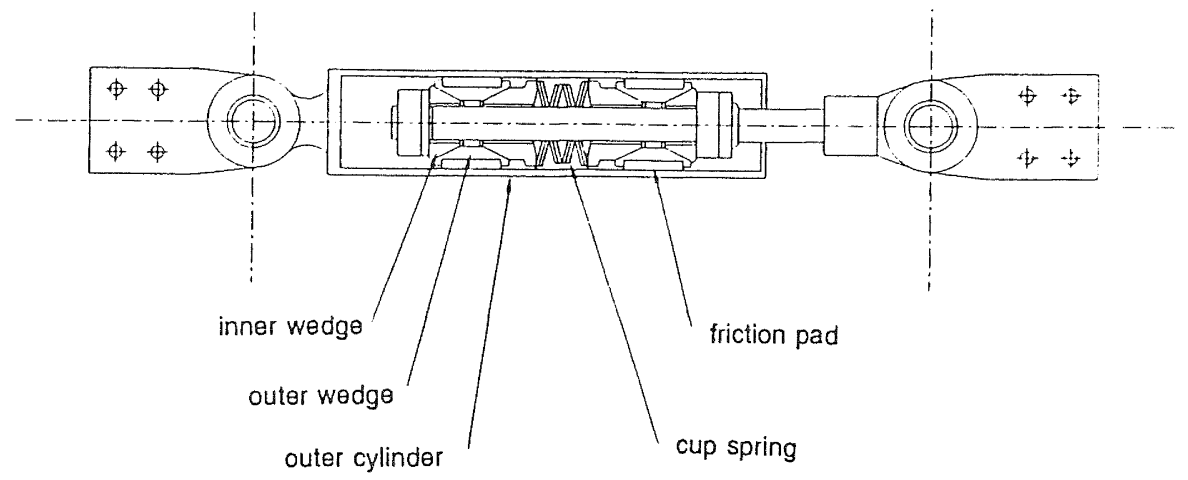

Fig. 6 Sectional View of Friction Damper 


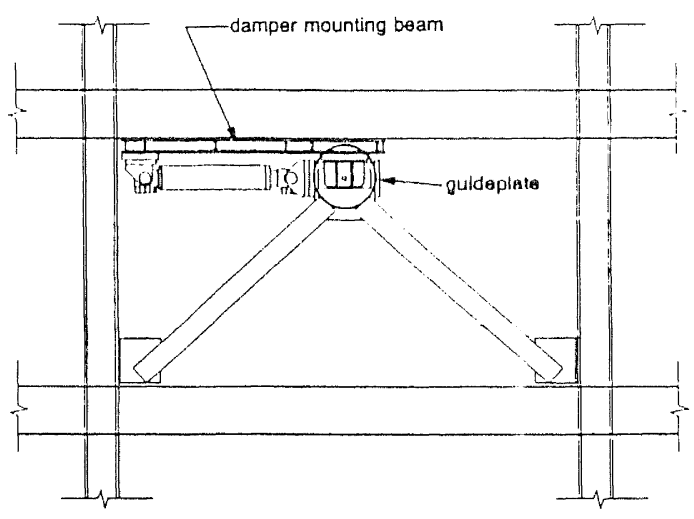

(a) Upper Floors (2 - 9), Dampers staggered at alternate levels

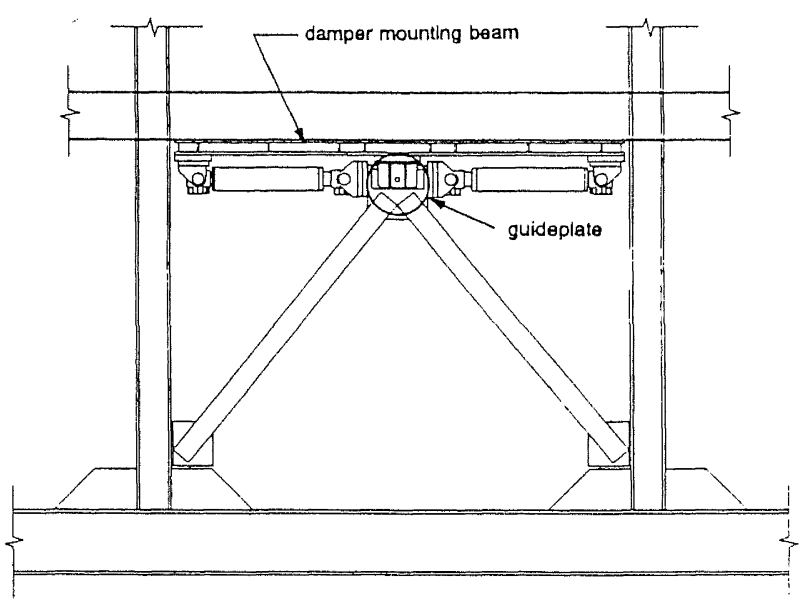

(b) Bottom Floor

Fig. 7 Installation of Friction Dampers in Model

\subsection{Design of damping systems for the model}

Friction dampers

The size (slip force) of the friction dampers and their layout in the test structure was determined using a nonlinear time-history analysis approach. An initial slip load distribution was chosen based on the results of a previous shake table study of the test structure containing another type of friction damper [2], and a series of analyses were performed for a number of different earthquakes at various input levels. The final slip load distribution was chosen as that which provided the lowest structural response for all of the inputs.

\section{Viscoelastic dampers}

The method used for the design of the VE dampers for the test structure was a simplified first-mode procedure aimed at providing the structure with a specified level of damping (10\%) at a nominal maximum displacement. This was done using an energy approach. A complete description of the procedure used is given in [1].

\subsection{Earthquake simulator study}

\subsubsection{Description of experiments}

The four configurations of the model structure (Figure 1) were subjected to a number of different dynamic tests. These were free vibration (pull-back), pulse, random noise, and earthquake tests. Fundamental frequencies for the MRF and CBF of 1.95 $\mathrm{Hz}$ and $2.95 \mathrm{~Hz}$, respectively, were identified. The dynamic characteristics of the VD and FD models were a function of the level and type of excitation, and were largely a result of whether or not the dampers were activated during the motion. From the results of the pulse tests, the fundamental frequencies of the VD (dampers activated) and the FD (dampers not activated) models were $2.30 \mathrm{~Hz}$ and $2.60 \mathrm{~Hz}$, respectively. A more detailed presentation of the diagnostic test results is given in [1]. The remaining discussion of results is devoted to those from some of the earthquake tests.

Fourteen different earthquake motions were used in the shake table tests of the MRF, CBF, FD, and VD structures. This paper discusses some of the results for the following earthquakes: 
(i) El Centro, Imperial Valley, May 18, 1940

(ii) Miyagi-ken-oki, Tohoku University, Sendai, June 12, 1978

(iii) Taft, Kern County, July 21, 1952

(iv) Llolleo, Chile, March 3, 1985

(v) La Union, Michoacan, September 19, 1985

\subsubsection{Earthquake test results}

Typical hysteresis loops for the two types of dampers are shown in Figure 8. The VE dampers exhibit elliptical hysteresis loops typical of materials with velocity-dependent properties. The loops are regular in shape and show stable behaviour. Throughout the VD model tests, the maximum VE damper shear strain was $208 \%$. Viscoelastic dampers have no threshold or activation force level, and thus they dissipate energy for all levels of earthquake excitation. This contrasts with the behaviour of the friction dampers, which for forces less than the slip force, do not slip and thus do not dissipate energy. The stiffness characteristics of the VE dampers are dependent on a number of factors, notably strain amplitude, frequency, and

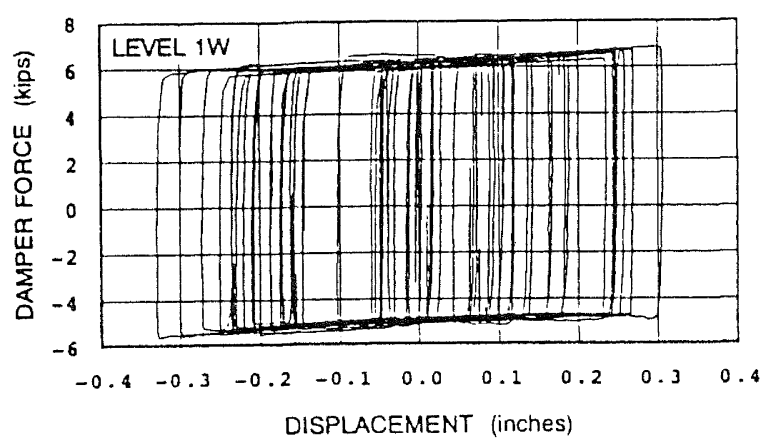

(a) Friction Damper - Chile-750 Test temperature. The variation of VE damper stiffness with shear strain for all the Miyagi tests is shown in Figure 9. Between strains of about 0 and $50 \%$, there is a large decrease in stiffness, but for strains in the range of about 50 to $200 \%$, the stiffness can be regarded as approximately constant. This assumption was utilized in the use of "effective" damper stiffnesses in the numerical analyses described below. Temperature increases in the VE material during earthquake shaking were small and did not significantly affect the behaviour of the VE dampers.

The friction dampers exhibited outstanding behaviour. Their hysteretic behaviour is extremely regular and repeatable. The devices showed almost no variation in slip load during earthquake motion, and from previous tests of individual dampers, their force-displacement response was known to be basically independent of loading frequency, amplitude, number of loading cycles, and temperature. In contrast to the VE dampers, the friction dampers are not activated during small excitations. Under such circumstances, the FD model behaved more as though it were a CBF.

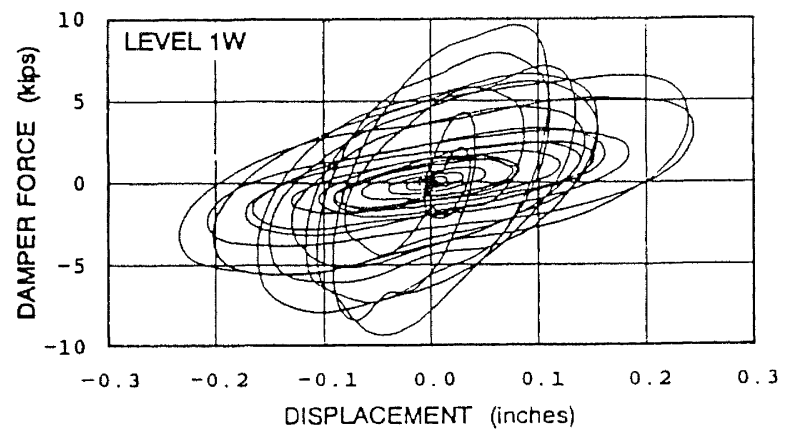

(b) VE Damper — Miyagi-300 Test

Fig. 8 Typical Damper Hysteresis Loops

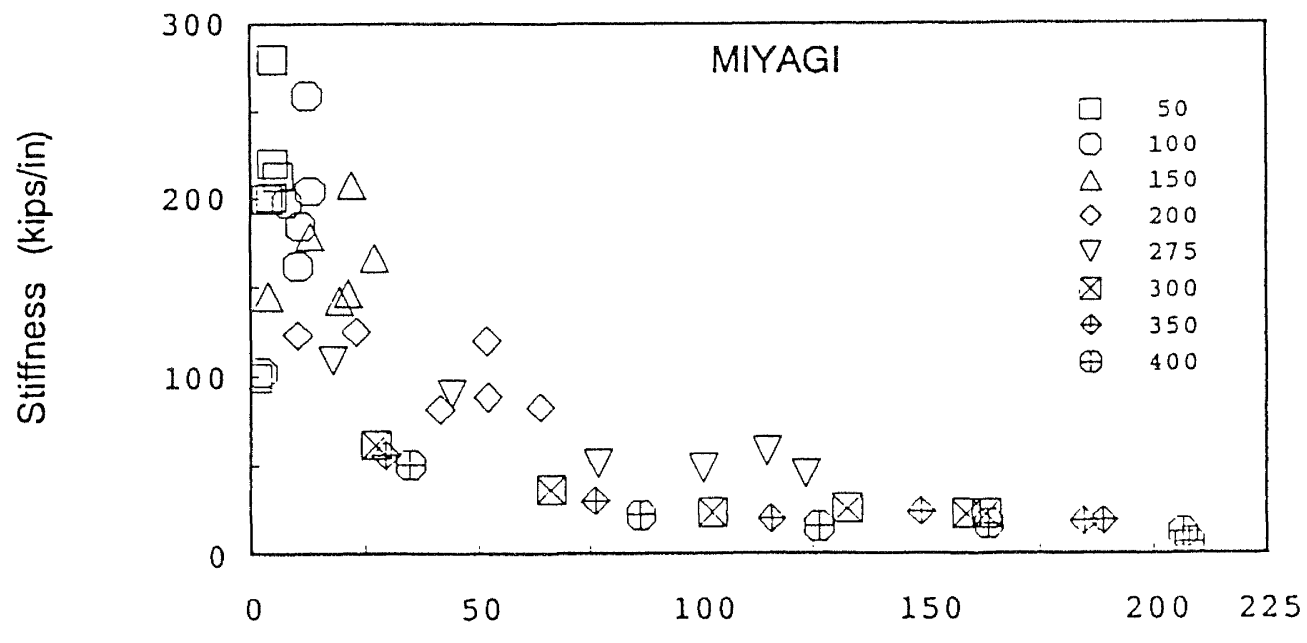

Shear Strain (\%)

Fig. 9 VE Damper Stiffness vs. Shear Strain for Miyagi Tests 
Because of the variation in VE damper stiffness with strain amplitude, the fundamental frequency of the VD structure also varied with excitation level, from $2.43 \mathrm{~Hz}$ down to $2.00 \mathrm{~Hz}$, compared with $1.95 \mathrm{~Hz}$ for the MRF. Low-level earthquake tests of the FD model revealed a fundamental frequency of 2.67 $\mathrm{Hz}$ (compared with 2.95 for the $\mathrm{CBF}$ ), while for large excitations, a variation of 2.47 to $2.35 \mathrm{~Hz}$ was observed.

Shake table response comparisons of the various systems were made wherever possible. For a sequence of El Centro and Miyagi tests, the VD model generally behaved in the same way as the CBF with regard to displacements, and in the same way as the MRF with regard to accelerations. The same general trends were also seen for the FD model compared with the CBF and MRF models. Peak base shears of the FD, VD, and MRF models for a series of Miyagi tests are compared in Figure 10 , where the FD and VD values are seen to be less than that of the MRF. This, coupled with the reduced drift levels achieved by the dampers, represents a significant overall improvement in response. A large number of equivalent tests were performed on the MRF, FD, and VD models. From response comparisons for the El Centro, Taft, and Miyagi sequences of inputs, drifts in both the FD and VD models were reduced by 10 to $60 \%$ over those of the MRF, while story accelerations were reduced by 25 to $60 \%$. In all cases, the FD and VD responses were reduced.

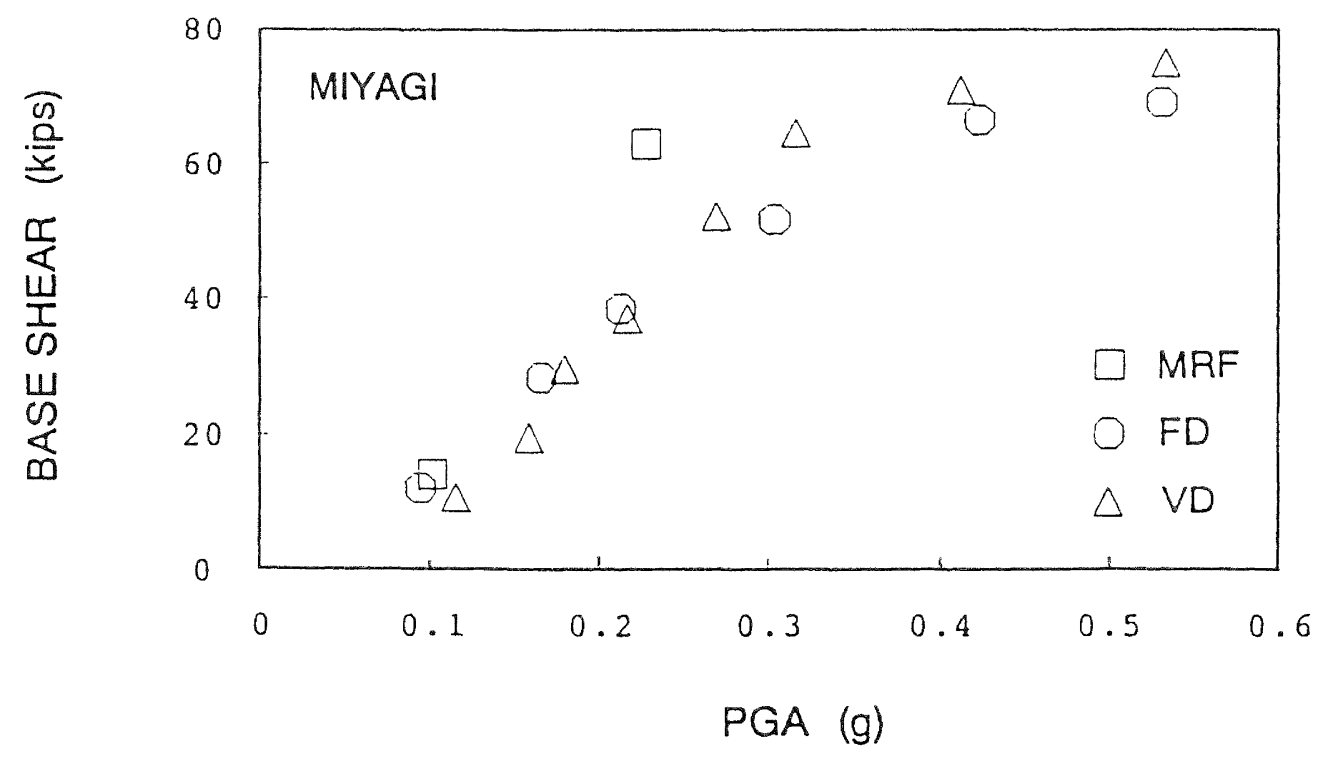

Fig. 10 MRF, FD, and VD Peak Base Shear vs. PGA for Miyagi Tests

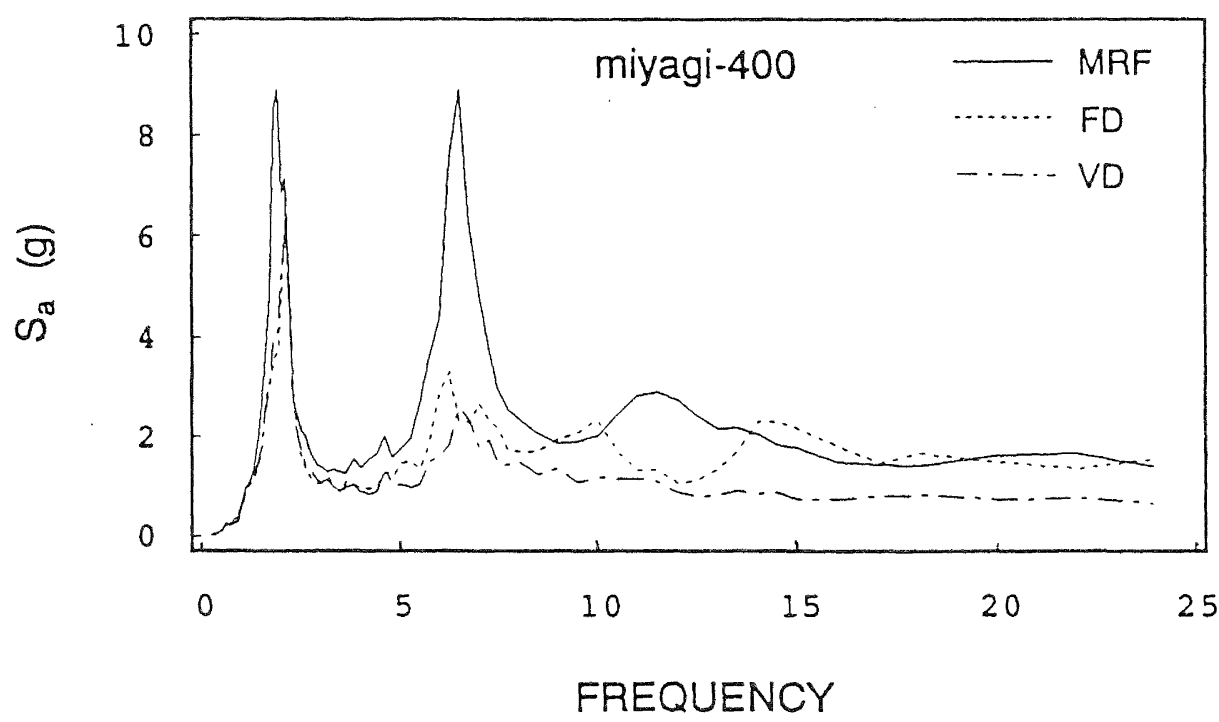

Fig. 11 MRF, FD, and VD Level $32 \%$-Damped Floor Response Spectra, Miyagi-400 Tests 
Floor response spectra were also used to compare the MRF, FD, and VD models. Two percent-damped spectra for the third floor of each of the models are presented in Figure 11 for the Miyagi-400 tests. The damped structures both offer significant reductions in spectral acceleration, particularly over the range of 5 to $10 \mathrm{~Hz}$. Above $10 \mathrm{~Hz}$, the VD spectrum is about half that of the MRF, while the FD spectrum is less than or about the same as that of the MRF. These results, and those for many other earthquake inputs, indicate that these two types of energy absorbers do not pose problems for internal equipment in structures, and in most cases actually provide improvements over the equivalent MRF.
The FD model was analyzed using a nonlinear analysis program. Good agreement with experimental results was obtained. Figure 12 shows MRF and CBF analysis results for the Chile-750 input. In contrast with these results, there was no yielding in the FD structure under this or any other input used in the test programme. The VD model also experienced no yielding in any of the earthquake tests. The stable hysteretic behaviour of the friction devices makes them particularly amenable to accurate modelling. A linear elastic analysis approach was used for the VD model. The analyses captured both the damping and stiffness characteristics of the VE dampers accurately. Very good results were obtained (Figure 13). These analyses permitted the separate effects of damping stiffness to be determined (Figure 14). The increased damping was found to be the major factor in improving the response of the VD model.

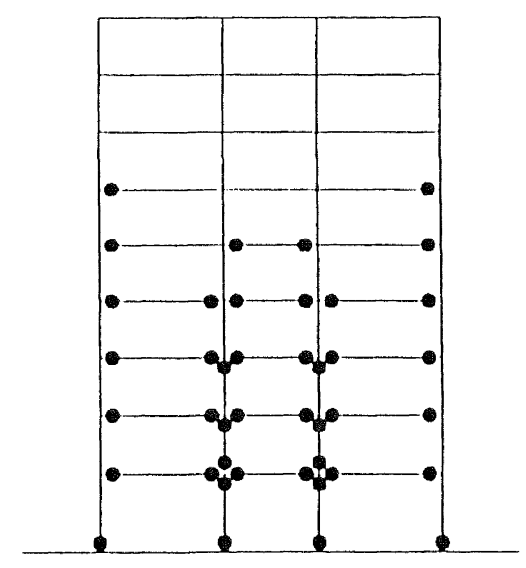

(a) MRF
- plastic hinge

- brace buckling

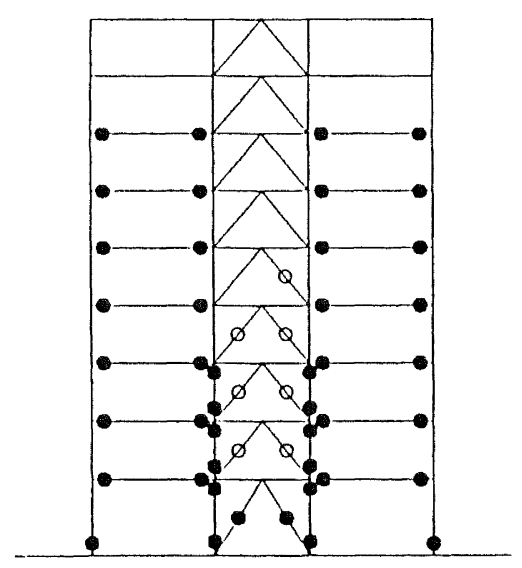

(b) $\mathrm{CBF}$

Fig. 12 Analytical Inelastic Demands, Chile-750 Input

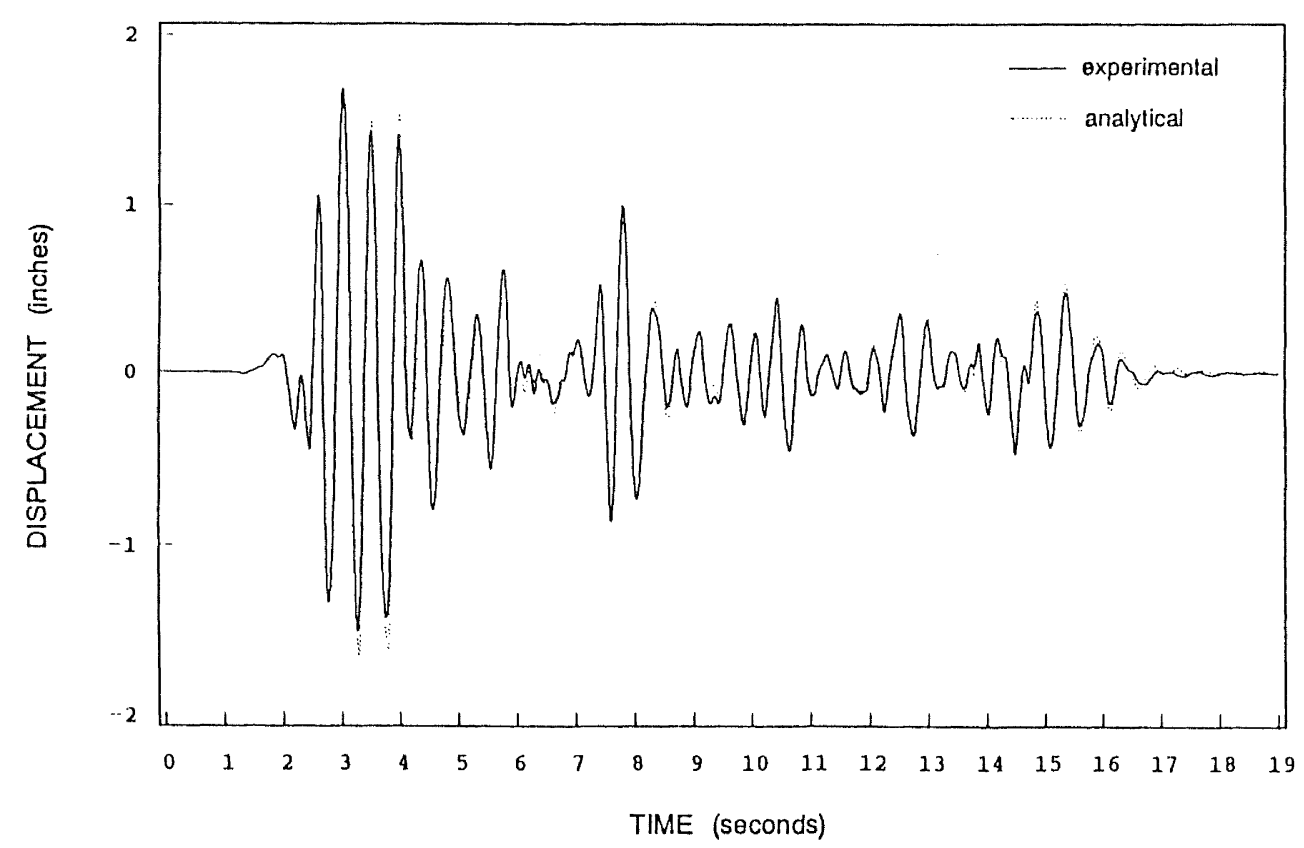

Fig. 13 VD Experimental and Analytical Roof Time Histories, El Centro-250 Input 


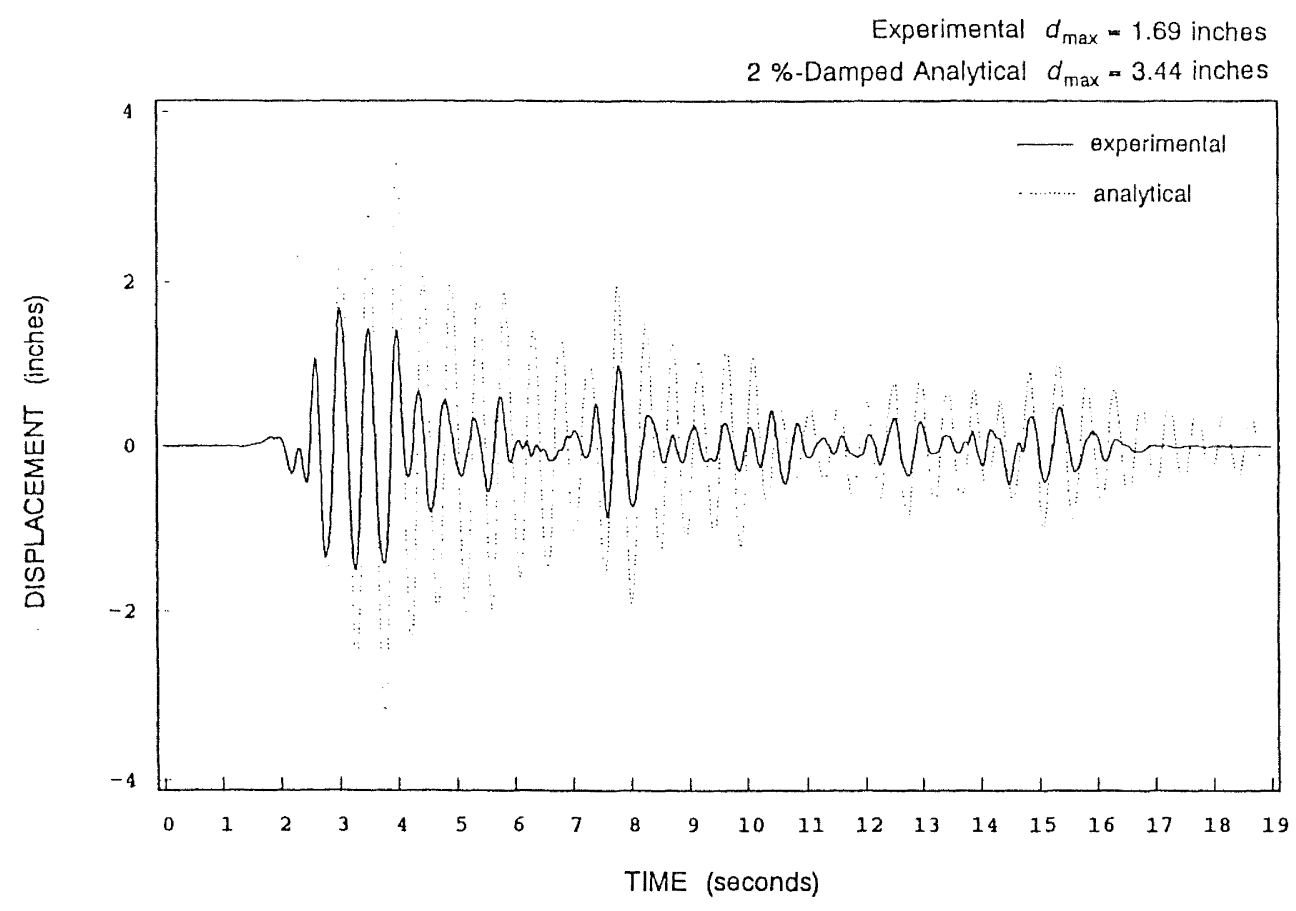

Fig. 14 VD Experimental and 2\%-Damped Analytical Roof Time Histories, El Centro-250 Input

\subsection{Conclusions}

Separate comparisons of the FD and VD systems with the "undamped" MRF and CBF structures showed that both damped systems behaved similarly to the CBF in terms of story drifts, and similarly to the MRF in terms of story accelerations and story shears. The FD and VD systems were remarkably similar with regard to acceleration and displacement responses for a wide selection of earthquake inputs. Peak base shears of the FD and VD models were similar for a range of input levels of the El Centro, Miyagi, and Taft signals. They are approximately the same as, or less than, the MRF maximum base shears. These results were achieved while simultaneously reducing the drifts to as little as one half of those of the MRF.

Floor response spectra showed spectral accelerations of both damped systems to be less than those of the MRF. Neither type of energy absorber caused undesirable high frequency response amplification in the frequency ranges important for internal equipment or nonstructural components.

This combined experimental and analytical study has demonstrated the response improvements possible through the use of energy absorbers. Existing analysis programs were used to model the structures equipped with energy absorbers, with good results. This should provide the basis for more detailed parametric analyses in the future.

\section{SMALL-SCALE EARTHQUAKE SIMULATOR TESTING OF FRICTION AND SHAPE- MEMORY ALLOY DAMPERS}

This section presents a summary of the test results of the Fluor Daniel, Inc. Energy Dissipating Strut (EDS) and tests studying the use of Nickel Titanium shape memory alloy (Nitinol) as an energy dissipating element. Both series of tests were performed on the same small-scale three-story steel frame. A more comprehensive presentation of these test results is provided in references [5, 6, and 7].

\subsection{Description of test facility and model structure}

A small shake table at the Earthquake Engineering Research Center was used for these tests. The table is $1.42 \mathrm{~m} \mathrm{x} 1.22 \mathrm{~m}$ $(4 \mathrm{ft} 8$ in $x 4 \mathrm{ft})$ in plan, with one horizontal degree-of-freedom and a payload capacity of $45 \mathrm{kN}$ (10 kips). The model was a three-story steel moment-resisting frame with all welded

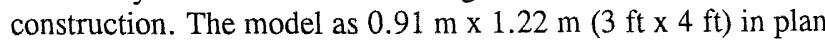
and the total weight was $18.9 \mathrm{kN}$ (4.02 kips), equally distributed between the floors. The damping of the bare model was $0.5 \%$, and the three translational frequencies in the direction of testing were $2.6 \mathrm{~Hz}, 10.9 \mathrm{~Hz}$, and $24.5 \mathrm{~Hz}$. 


\subsection{Energy Dissipating Strut}

The Energy Dissipating Strut (EDS) was originally developed as a seismic restraint device for the support of piping systems in nuclear power plants [5]. The mechanism of the EDS is sliding friction through a range of motion with a stop at the end of that range of motion. The outstanding features of the device are its self-centering capability and that the frictional force is proportional to the displacement. Figure 15 shows overall and cross-sectional views of the device. Depending on the spring constant of the core, the initial slip load, the configuration of the core, and the gap size, several different types of hysteretic behaviour are possible. Two typical hysteresis loops for different adjustments of the device obtained from testing are shown in Figure 16.

\subsubsection{EDS test program}

The EDS frame tests used two earthquake ground motions: El Centro (1940, S00W component, 1/2 time scale) and Zacatula (1985 Michoacan). The El Centro signal has a strong initial pulse while the Zacatula signal is more regular.

Six EDSs were mounted in the model: two at each story. Figures 17 and 18 are sketches of the model without and with the EDSs in place. Figure 19 is a view of the EDSs installed in the second level of the model.

The principal variable changed during the testing was the initial slip load, and for the majority of the tests performed, the slip load distribution was uniform throughout the model. In addition to the tests with the device in the self-centering configuration, a series of tests with the EDS configured to act as a simple Coulomb device were performed.

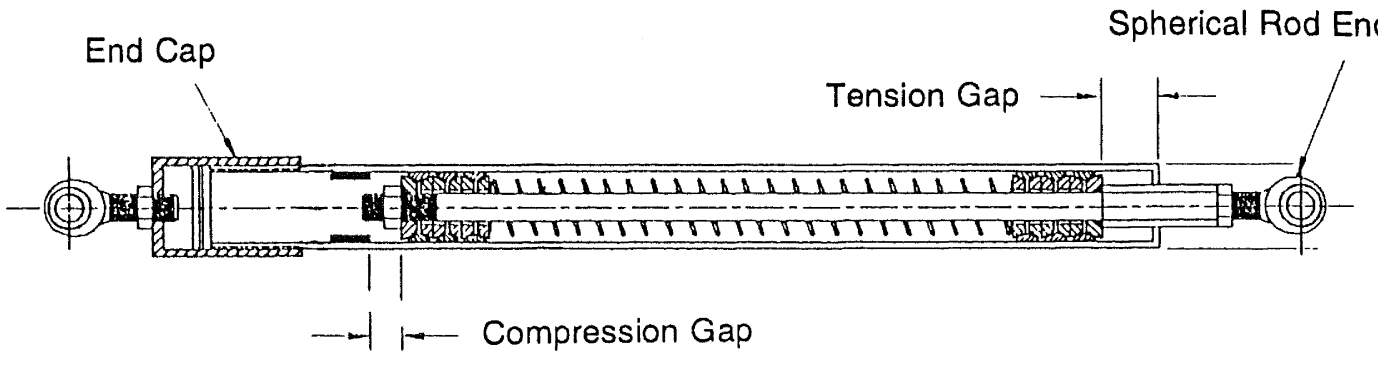

Fig. 15 Sectional View of Energy Dissipating Strut

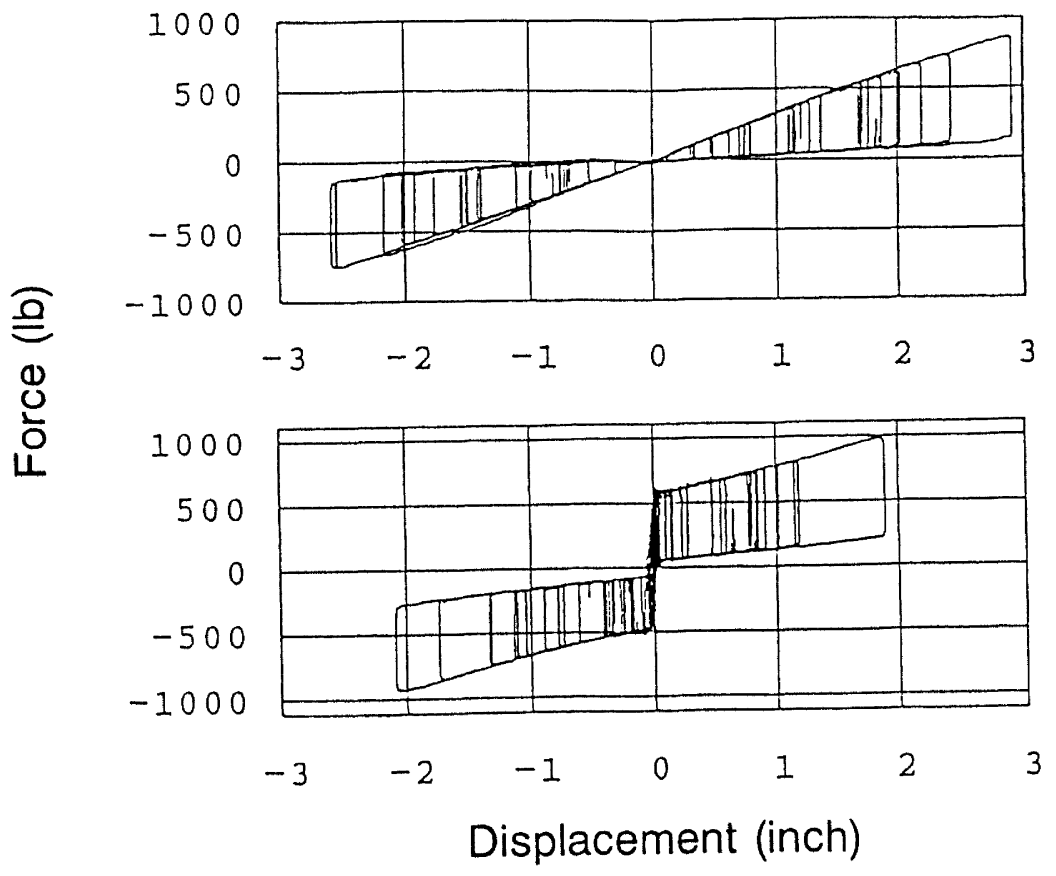

Fig. 16 Hysteresis Loop Shapes For Different Adjustments of the EDS 


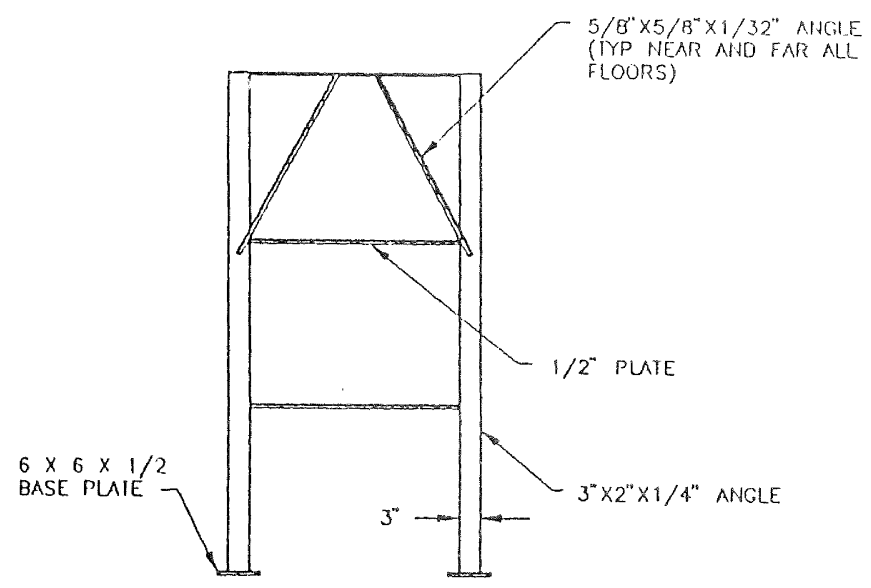

Section

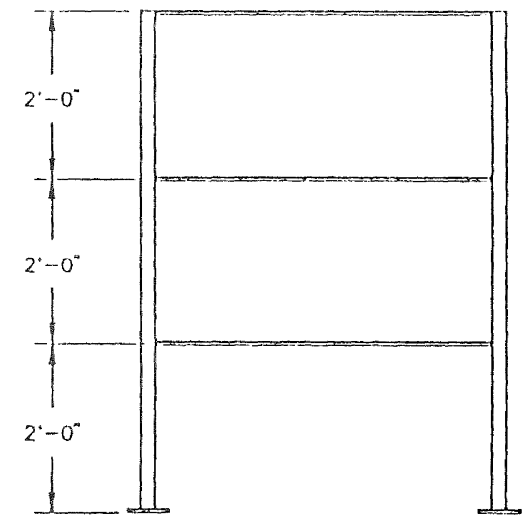

Shaking Elevation

Fig. 17 Bare Frame

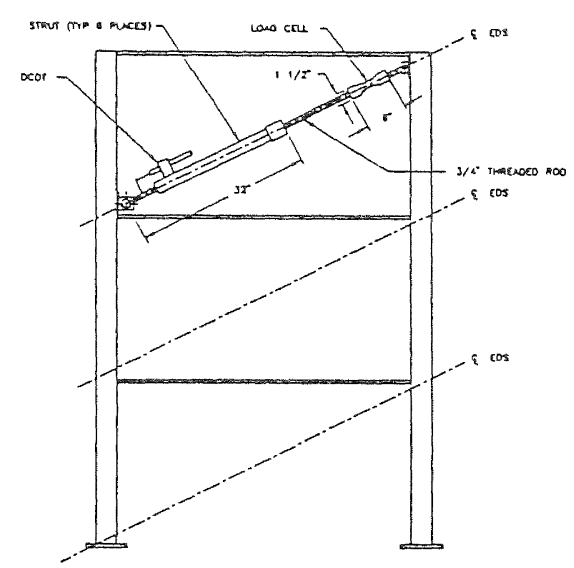

Fig. 18 Frame with Energy Dissipating Struts

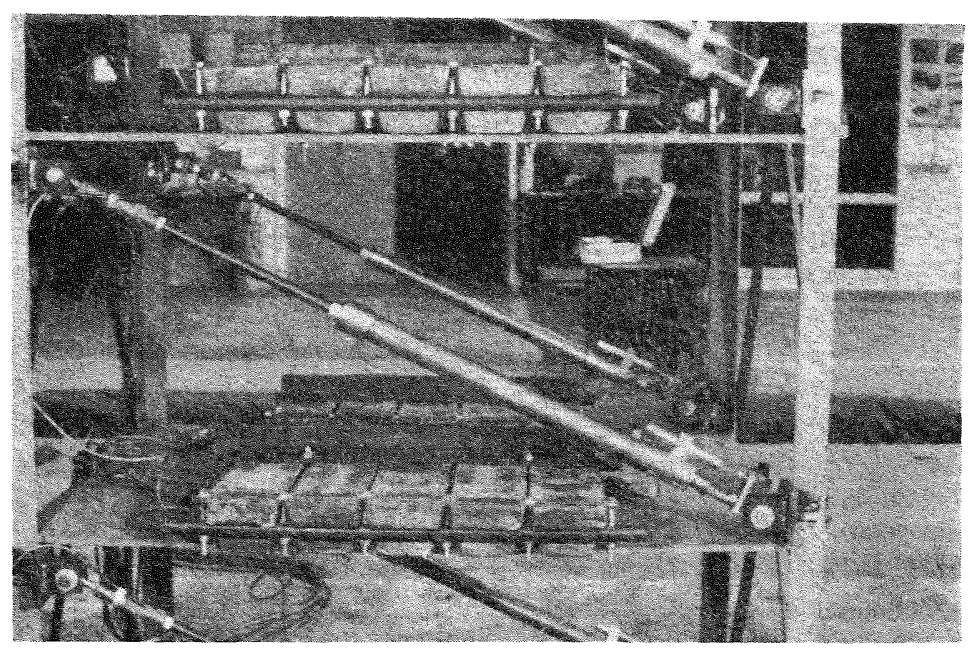

Fig. 19 View of EDSs Installed at Second Level of Frame 


\subsubsection{Summary of test results}

Figures $20 \mathrm{a}$ and $\mathrm{b}$ show profiles of the peak accelerations, interstory drifts, and displacements relative to the ground for the El Centro (peak ground acceleration $(\mathrm{pga})=0.33 \mathrm{~g}$ ) and the Zacatula (pga $=0.36 \mathrm{~g}$ ) inputs. On each figure, the response of the bare frame and the EDS with slip loads of 335, 555, 890, and $1335 \mathrm{~N}(75,125,200$, and $300 \mathrm{lbs})$ are compared.

The overall effect of the EDS is to substantially reduce the model deformations and interstory drifts. Interstory drifts and displacements consistently decrease with increasing slip load. Accelerations are not so well behaved: increasing the slip load sometimes causes an increase in the accelerations. This is a result of the friction behaviour and a consequence of making the structure stiffer. Because of the impulsive nature of the $\mathrm{El}$ Centro signal compared to the Zacatula motion, there is a larger reduction in response for the latter signal.

Part of the change in structural response is due to the change in the stiffness of the structure when the EDSs are added and part is due to the additional damping the EDSs add to the structure. The change in stiffness was substantial, with the highest frequency being $3.9 \mathrm{~Hz}$ for the braced frame. The shift in frequency depended on the slip load, the slip load configuration, and the frequency content of the input. A series of linear elastic response spectrum analyses were used to approximately segregate the effects of damping and stiffness. The response spectrum analysis was performed using the measured predominant frequency and mode shape for the braced model, but the damping was taken as that of the unbraced frame. The response spectrum results show the relative displacement of the frame with the shifted frequency and changed mode shape, but with the $0.5 \%$ damping of the unbraced frame. This approach isolated the relative effects of added damping and added stiffness to the response of the model. Because the mode shape does not change a great deal as the slip load varies, all the results can be normalized to one spectrum analysis curve. The reduction in response below this level is due to the added hysteretic damping of the EDSs. Figure 21 shows the results of a series of response spectrum analyses for the Zacatula signal. These figures present the seminal result of the EDS strut testing: the additional damping provided by the EDS significantly reduces the structural response. It can be seen from these figures that the damping contributes substantially to the reduction in relative displacement and that the higher the slip load the greater the reduction in response.

One advantage of the EDS is that it can be effective at low seismic levels or for wind loading while also being effective at high seismic levels. This is because the slip forces, and thus the energy dissipated, are proportional to the displacement of the EDS. Another advantage is that the self-centering behaviour would tend to reduce permanent offsets if the structure were deformed inelastically.

The testing revealed some problematical aspects of EDS behaviour. The EDSs were more effective in reducing the response of the model to relatively harmonic excitations than for impulsive excitations. The accelerations in the higher modes sometimes increased as the slip load increased, due to the sticking inherent in friction action. In design, this means that there may be a tradeoff between reduced structural deformations and higher acceleration responses in some frequency ranges.

\subsection{Shape memory alloy}

The shape memory effect in metals was first observed in the 1930s. In 1962, researchers at the Naval Ordinance Laboratory observed the phenomenon in Nickel-Titanium. Shape memory alloys (SMAs) have the capacity to undergo large strains and subsequently recover their initial configurations. The basis for this behaviour is that rather than deforming in the usual manner of metals, shape memory alloys undergo transformations from the austenitic to the martensitic crystal phase [3].

Among the growing number of applications of SMAs, the largest single use to date has been in hydraulic pipe couplings. The coupling is cooled to expand its diameter, assembled, and then as it warms to room temperature it recovers its smaller diameter and locks. Other SMA applications are circuit-board connectors, eyeglass frames (with shape memory or superelastic properties), blood clot filters that are inserted into veins and expand due to body temperature, and a number of other medical and dental applications.

In most current commercial applications, the phase change is temperature induced. However, the phase change can be stress induced at room temperature if the Nitinol has the appropriate formulation and treatment. This stress-induced phase change behaviour is referred to as superelasticity. Figure 22 illustrates the theoretical behaviour of Nitinol as it is loaded in tension. The key characteristic is that if the strain is less than the elastic limit strain, there is no permanent deformation. In this testing, Nitinol wire was incorporated in series as part of a cross bracing system in the model. In this configuration, the Nitinol was loaded only in tension, which allowed the full volume of the Nitinol to effectively dissipate energy. A view of the Nitinol cross bracing in the top floor of the model is shown in Figure 23a, and a close-up view of the Nitinol wire is shown in Figure $23 \mathrm{~b}$

\subsubsection{Summary of test results}

Figure 24 shows the behaviour which was achieved with no preload in the Nitinol wire. Because there was no preload, the wire was able to go slack during compressive portions of the dynamic loading, and as expected, the hysteresis loop shows this behaviour for strains up to $4 \%$. One desirable feature of the Nitinol is that its strength increases when the elastic limit strain is exceeded. This means that if the predicted earthquake excitation was exceeded, the structure would stiffen rather than soften. When the strain in the material was increased to $8 \%$, the hysteretic behaviour shown in Figure 25 was obtained. This loop shows all the characteristics which are theoretically predicted and were exhibited in the static tests. In these loops, there was no preload, and because permanent deformation of the wire occurred during the larger strain cycles, the wire was loose at the end of the test.

With a small preload, it was difficult to achieve uniform behaviour in all six braces. To resolve this problem, a large preload was applied to the Nitinol (Figure 26). With the preload applied, the strain in the Nitinol was between $2.5 \%$ and $6 \%$ throughout the testing. Thus, the Nitinol was continuously cycled in the region of hysteresis behaviour where the most energy is dissipated. With this loading, the Nitinol behaved smoothly in every brace, and the behaviour was uniform in all of the braces. This is illustrated in Figure 27, which shows hysteresis loops for both braces in each of the three floors. The 
(a) El Centro
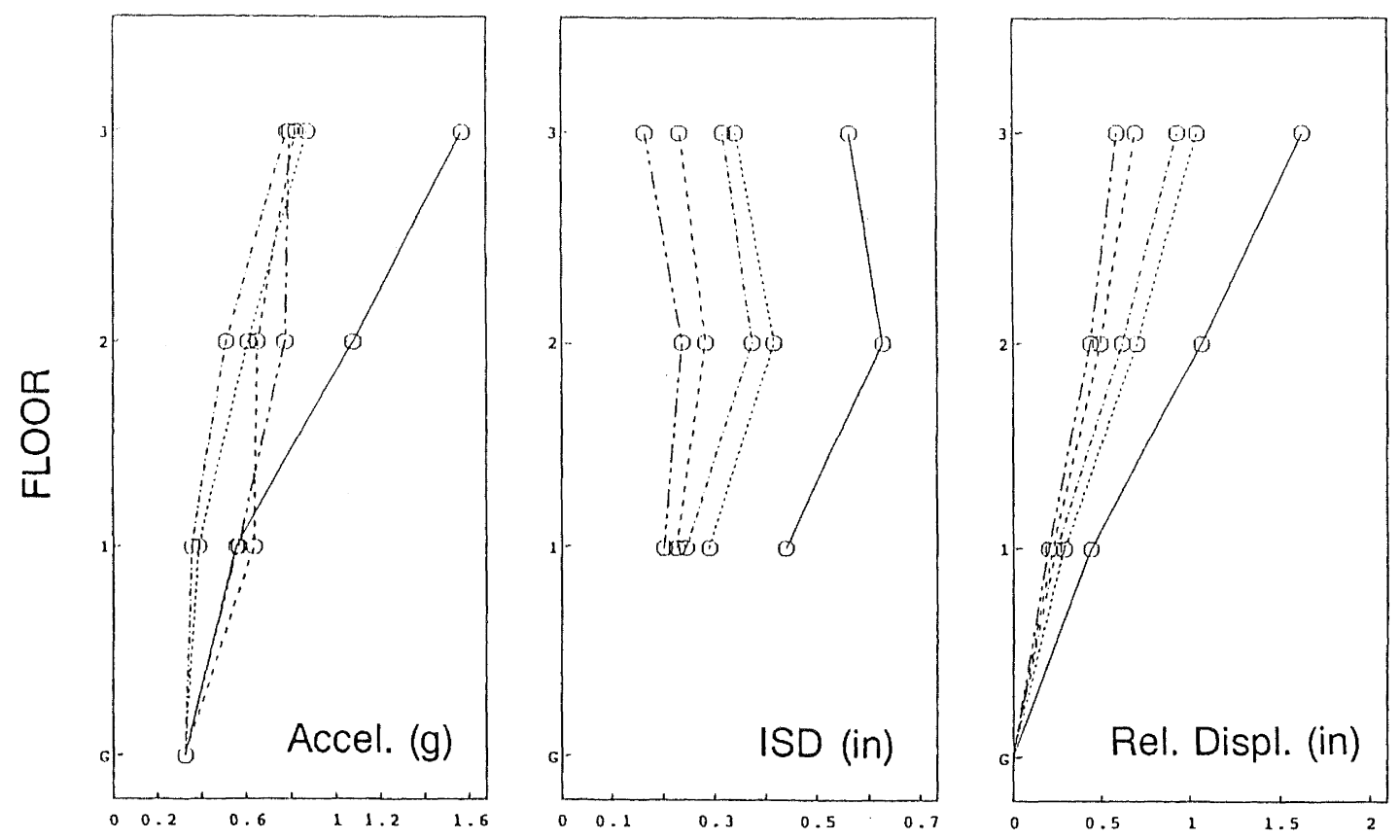

Solid: Bare Frame Dotted: EDS.75 Dot-Dash: EDS.125

Dashed: EDS.200 Dot-Dot-Dash: EDS.300

(b) Zacatula
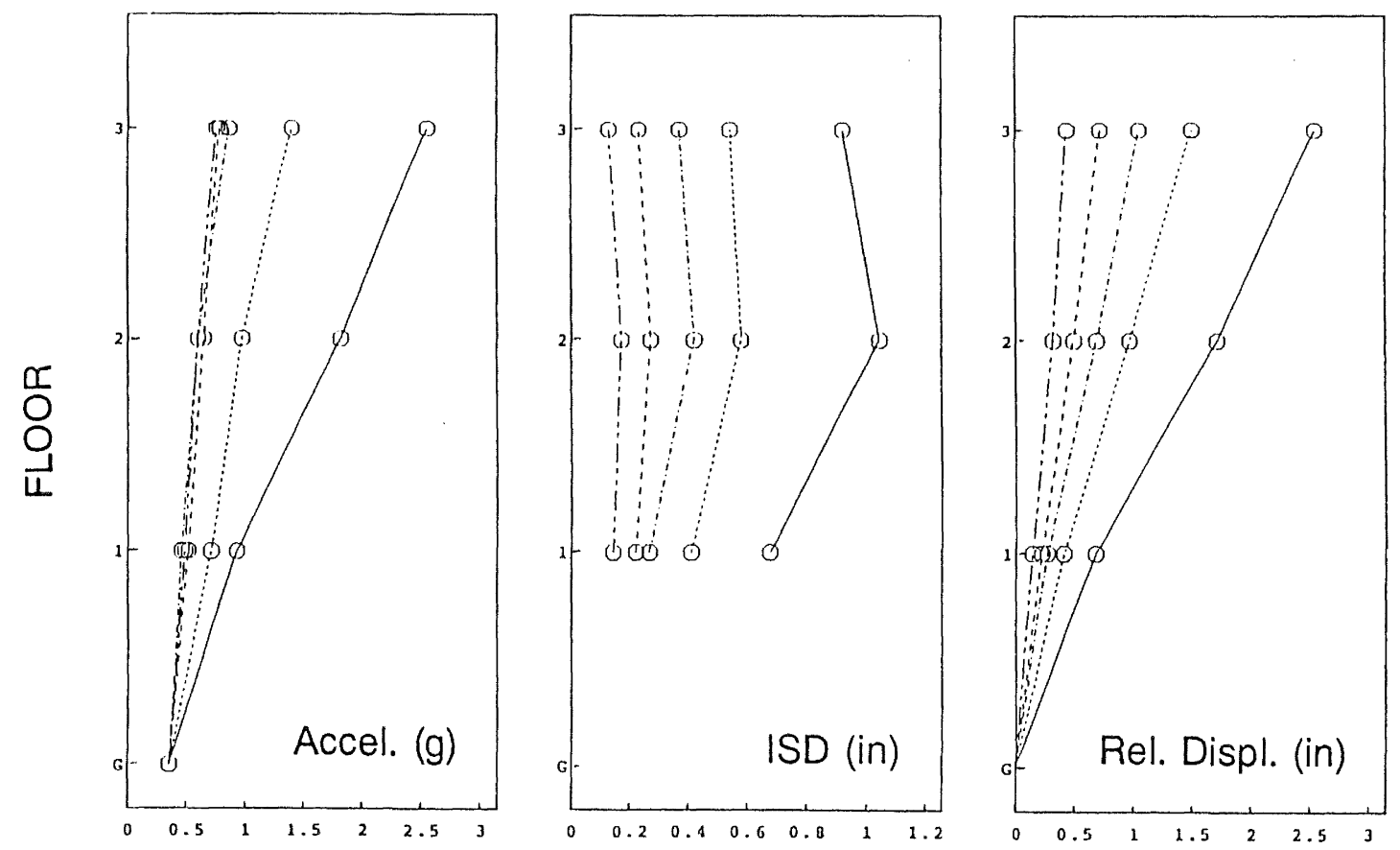

Solid: Bare Frame Dotted: EDS.75 Dot-Dash: EDS.125

Dashed: EDS.200 Dot-Dot-Dash: EDS.300

Fig. 20 EDS Frame Response Profiles 
upper pair of figures is for the top floor, the middle pair for the second floor, and the lower pair for the bottom floor. The loops for all of the floors are similar, and all loops exhibit significant dissipated energy.

The effect of the Nitinol braces on the seismic response of the model under the Zacatula motion is shown in Figure 28. The form and nomenclature in this figure are the same as the equivalent figures for the EDS. Results are shown for the bare frame, the frame with the Nitinol allowed to go slack, and the Nitinol with preload. The addition of the Nitinol braces significantly reduced the response in both cases. However, the preloaded Nitinol braces caused a greater reduction in all three response parameters. As was found for the EDS, the Nitinol energy dissipator was more effective for the regular Zacatula motion than for the impulsive El Centro motion.

\subsection{Conclusions}

The Energy Dissipating Strut (EDS) is a friction-based mechanical energy dissipator which has a wide range of possible hysteretic behaviours. The most interesting behaviour exhibits fat "S-shaped" loops and is self-centering. In this configuration, the friction force dissipating the energy is proportional to the displacement and the internal preload of the EDS. By its design, the EDS increased both the stiffness and damping of the model. The influence of the added damping was shown to contribute significantly to the reduction in response. One advantage of the EDS is that it can be effective at low seismic levels or for wind loads, while also being effective at high seismic levels. This is because the energy dissipated is proportional to the displacement of the EDS. The accelerations in the higher modes sometimes increased as the slip load increased due to the sticking inherent in friction action. The testing has established the potential of the EDS as an energy dissipator for building applications.

Nitinol demonstrated the special ability to yield repeatedly and not lose its preload. The damping in the structure increased from $0.5 \%$ to $3 \%$, and all of the structural responses were reduced. A Nitinol energy dissipator has the particular advantages of being mechanically very simple and reliable.

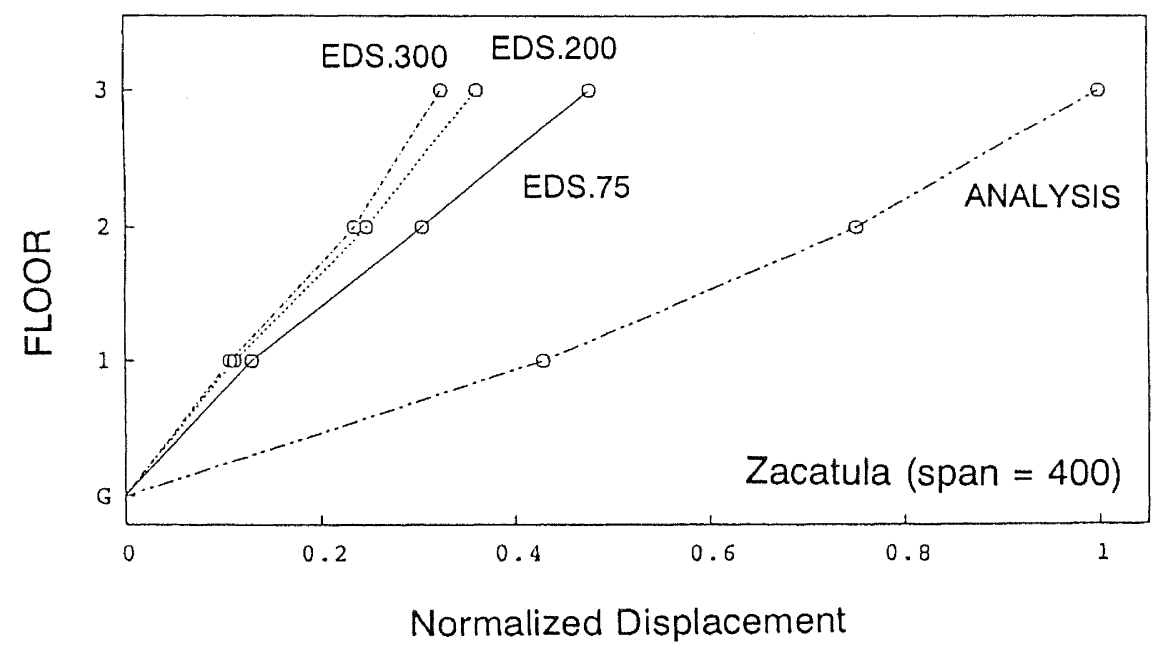

Fig. 21 Effect of Damping on Response - Experimental and Analytical Response Profiles

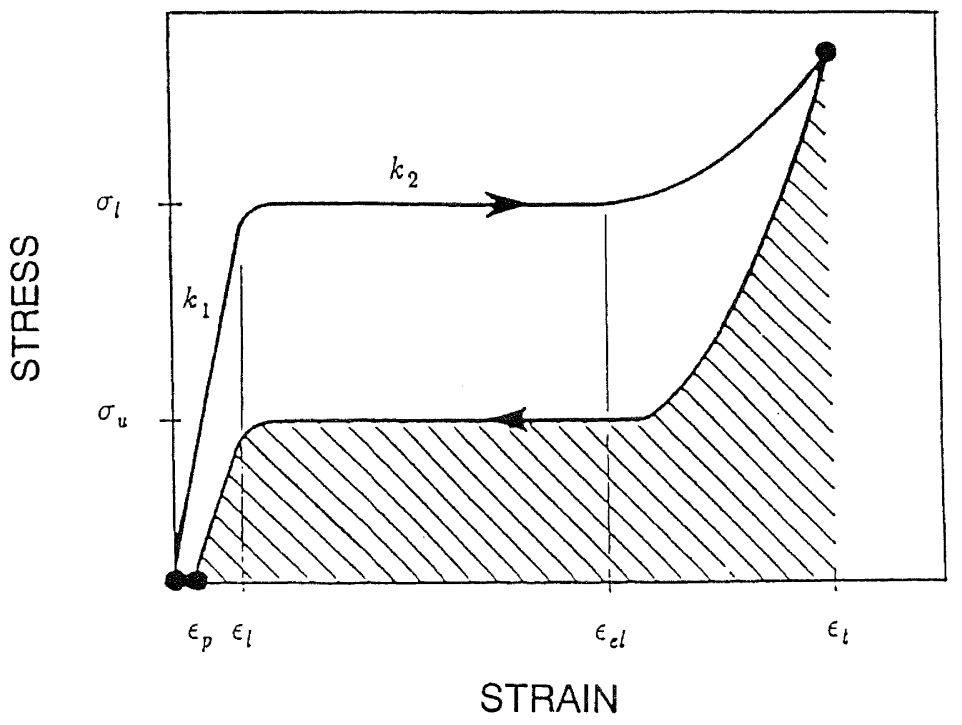

$$
\begin{aligned}
& \varepsilon_{p}=\text { permanent strain } \\
& \varepsilon_{l}=\text { critical loading strain } \\
& \varepsilon_{e l}=\text { elastic limit strain } \\
& \varepsilon_{t}=\text { total strain } \\
& \sigma_{l}=\text { critical loading stress } \\
& \sigma_{u}=\text { critical unloading stress } \\
& k_{1}=\text { initial stiffness } \\
& k_{2}=\text { reduced stiffness }
\end{aligned}
$$

Fig. 22 Superelasticity 

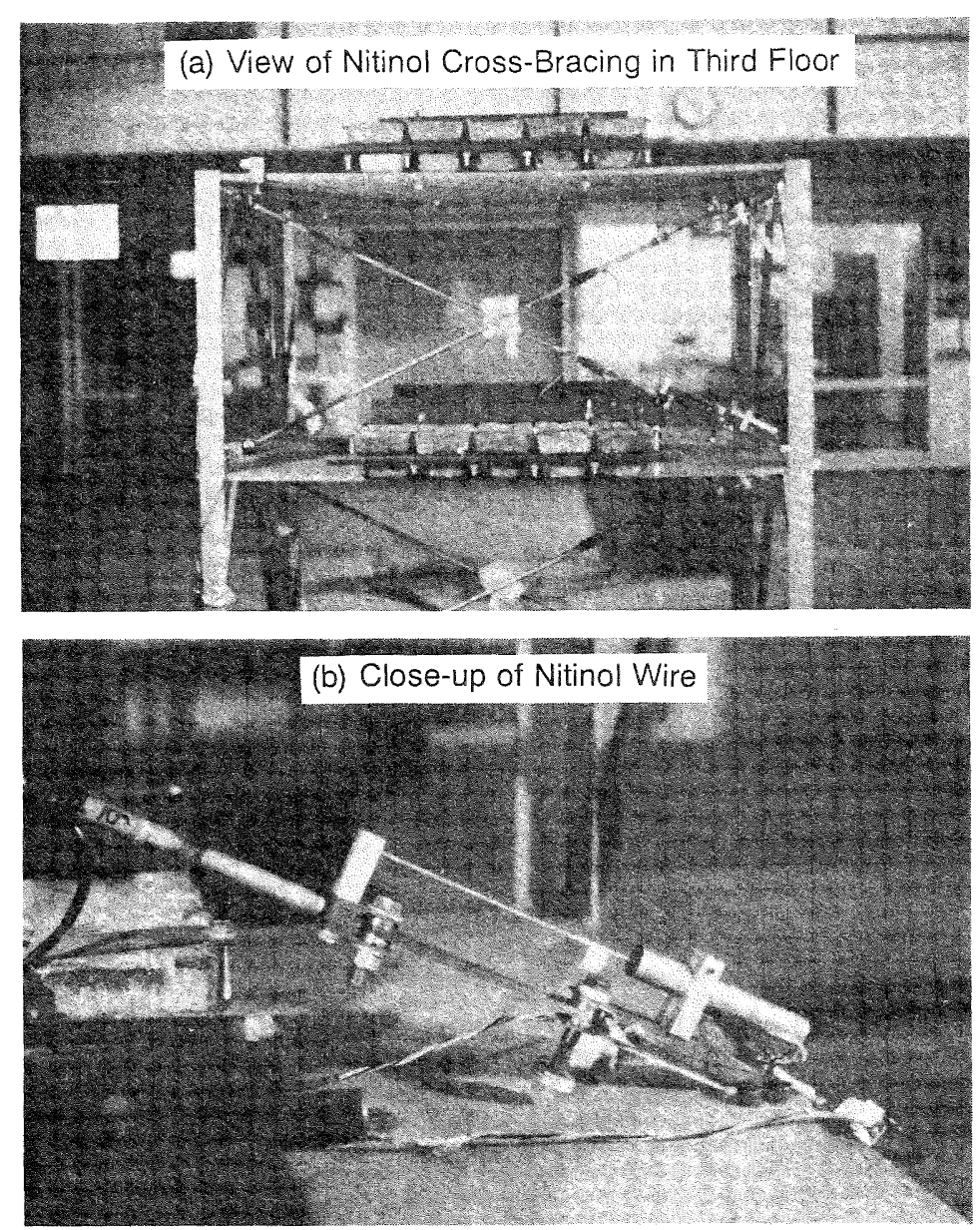

Fig. 23 Installation of Nitinol Wire in Model Bracing

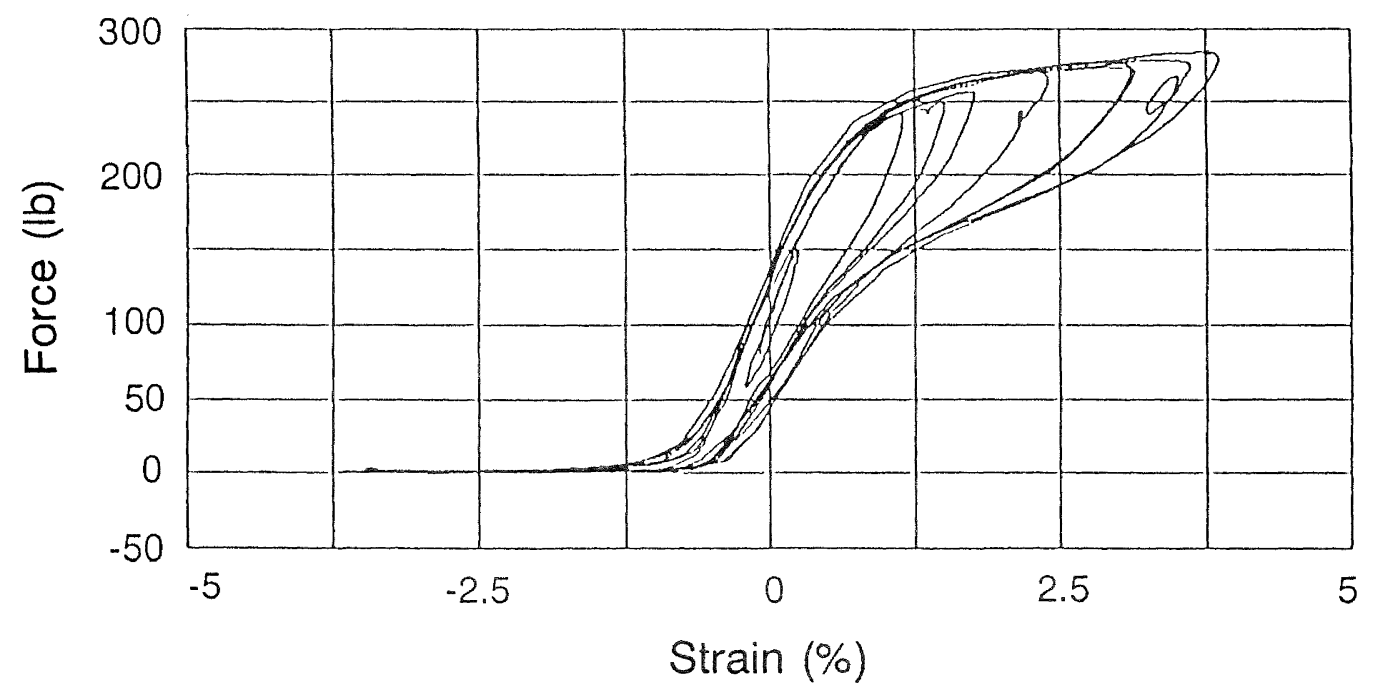

Fig. 24 Nitinol Moderate Strain Hysteresis Behaviour 


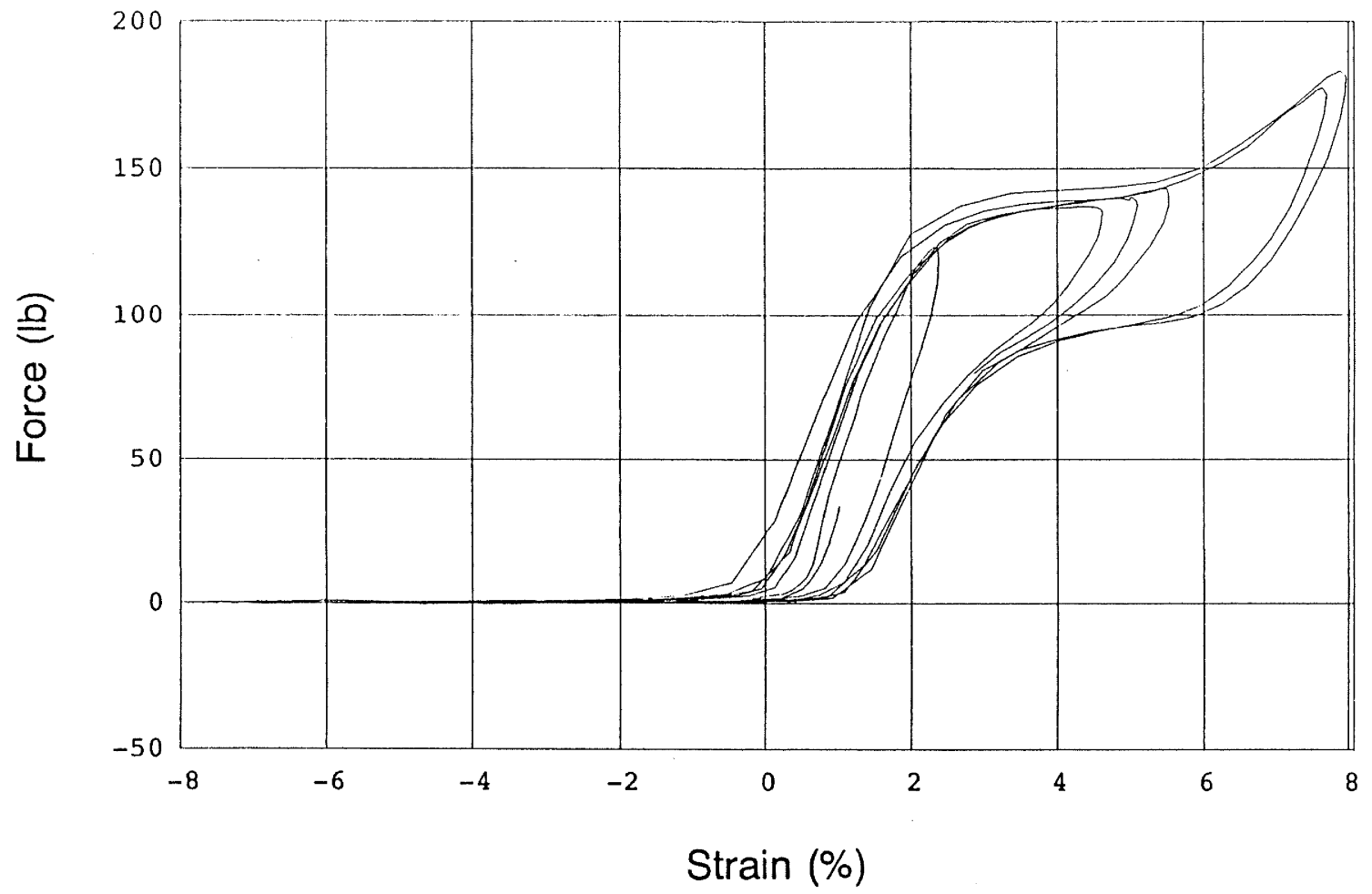

Fig. 25 Nitinol High-Strain Hysteresis Behaviour

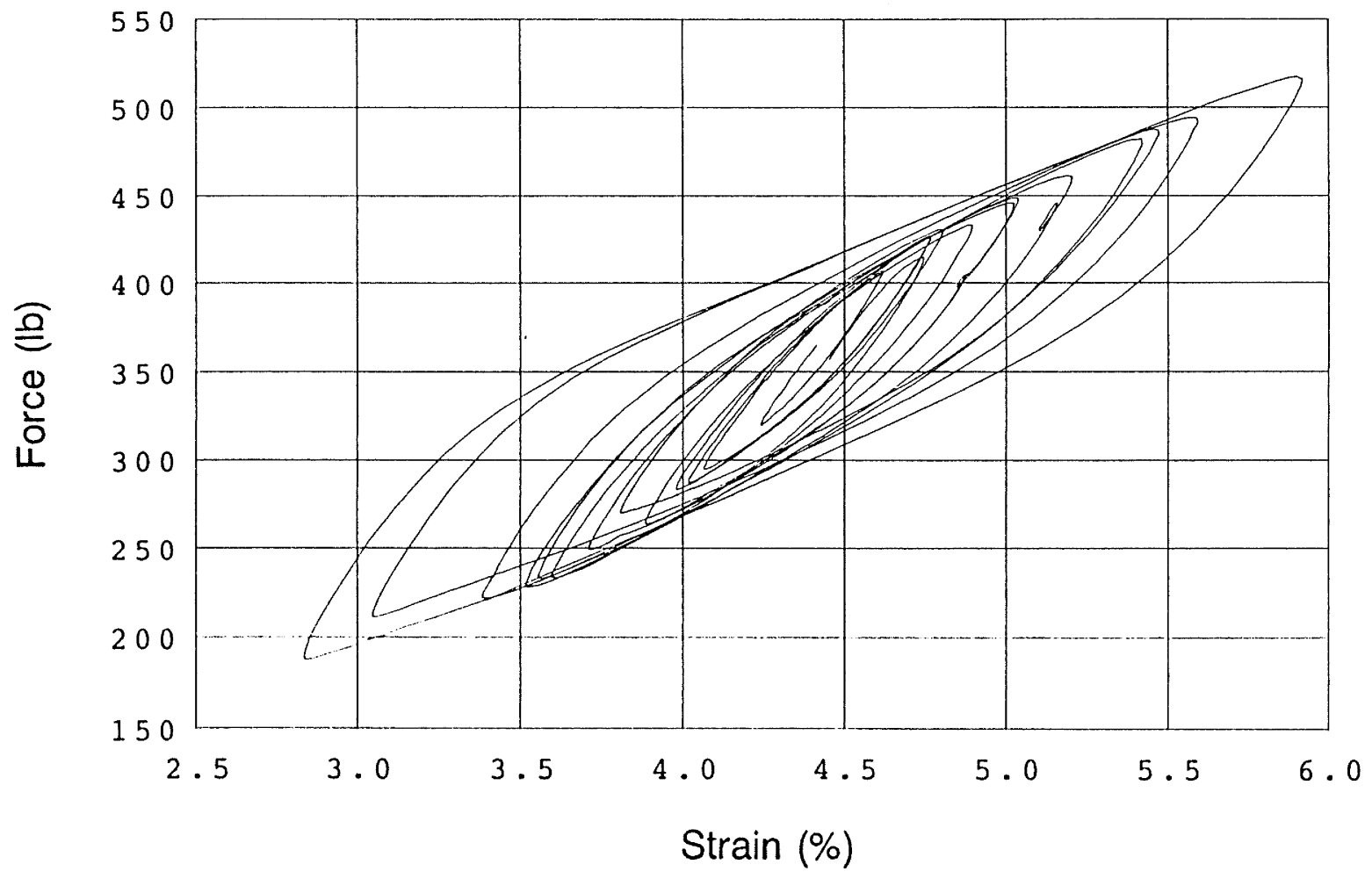

Fig. 26 Nitinol Hysteresis Behaviour with Pre-Strain Applied 

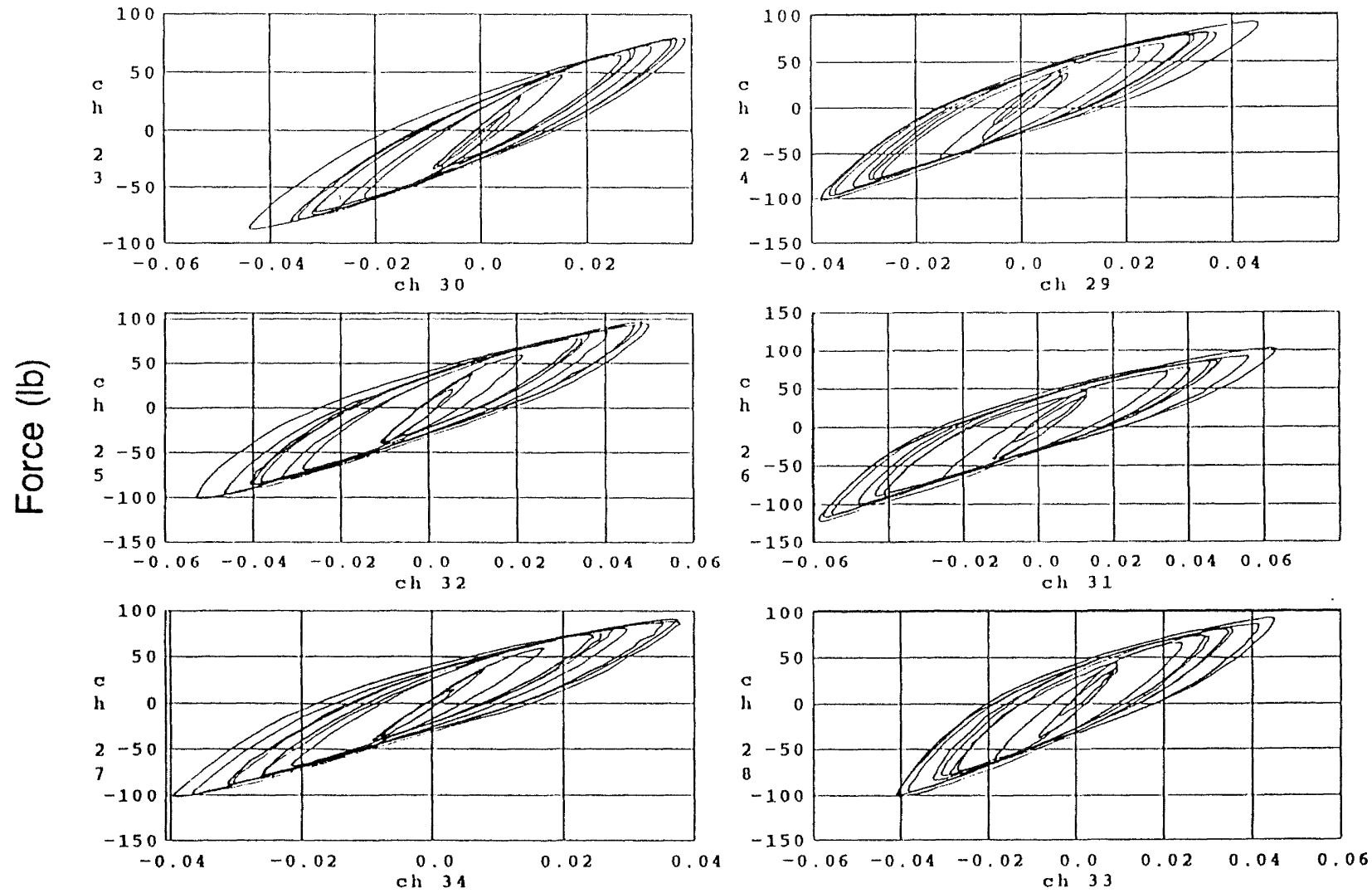

Displacement (inch)

Fig. 27 Hysteresis Loops for all Nitinol Braces from a Typical Test
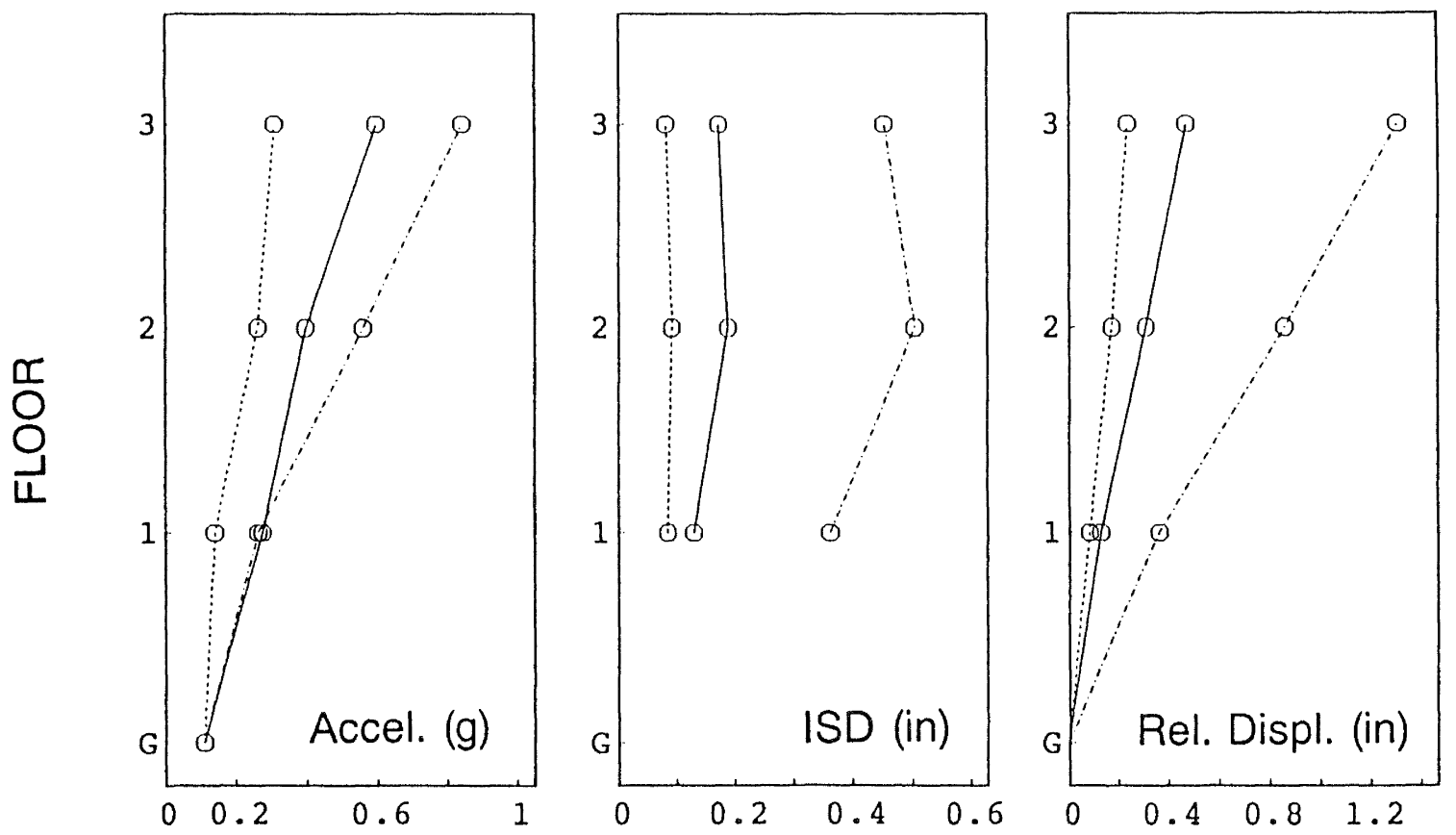

Solid: 20 Strnds Slk, Dotted: 20 Strnds Prld, Dot-Dash: Bare

Fig. 28 Effect of Nitinol Braces on Response - Zacatula (span $=100)$ 


\section{OVERALL CONCLUSIONS}

Four different types of passive energy dissipators were tested under earthquake shaking conditions in two different model structures. Large-scale tests of a nine-story steel frame incorporating friction dampers and then viscoelastic dampers, and small-scale tests of a three-story steel model incorporating friction dampers and then shape memory alloy dampers were performed. The effectiveness of the various types of dampers were evaluated by comparing the response of the structures containing the dampers with the response of the same structures with no dampers, or with conventional types of bracing. The benefits of the energy dissipators have been demonstrated by these comparisons, and also by various analytical studies. The improvements in performance have been shown to stem primarily from the increase in energy dissipation available within the structure, and only to a lesser extent from the change in response frequency caused by the additional stiffness of the bracing by which the dissipators are connected in the structure.

\section{REFERENCES}

1. Aiken, I.D. and Kelly, J.M. 1990. "Earthquake Simulator Testing and Analytical Studies of Two Energy-Absorbing Systems for Multistory Structures." Report No. UCB/EERC-90/03, Earthquake Engineering Research Center, University of California at Berkeley.

2. Aiken, I.D., Kelly, J.M., and Pall, A.S. 1988. "Experimental Study of Friction Damping for Steel Frame Structures." Proceedings, ASME PVP Conference, (PVP-133): 95-100.
3. Hodgson, D. 1988. "Using Shape Memory Alloys." Shape Memory Applications, Cupertino, California.

4. Mahmoodi, P. 1972. "Structural Dampers." Journal of the Structural Division, ASCE 95(ST8): 16611672 .

5. Nims, D.K. 1991. "Large-Scale Experimental Study of Two Alternate Support Systems for the Seismic Restraint of Piping." Ph.D. Dissertation, University of California at Berkeley.

6. Nims, D.K. and Kelly, J.M. (to be published). "Experimental Evaluation of a Friction Device for Energy Dissipation and Base Isolation." UCB/EERC Report, Earthquake Engineering Research Center, University of California at Berkeley.

7. Richter, P.J., Nims, D.K., Kelly, J.M., and Kallenbach, R.M. 1990. "The EDR-Energy Dissipating Restraint, A New Device for Mitigating Seismic Effects." Proceedings, 1990 Structural Engineers Association of California Convention at Lake Tahoe.

8. Uang, C.M. and Bertero, V.V. 1988. "Use of Energy as a Design Criterion in Earthquake Resistant Design." Report No. UCB/EERC-88/18, Earthquake Engineering Research Center, University of California at Berkeley.

\section{UNITS}

$1 \mathrm{kip}=1000 \mathrm{lb}=4.448 \mathrm{kN}$

$1 \mathrm{inch}=25.4 \mathrm{~mm}$ 